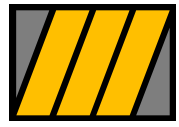

ESCUELA DE NEGOCIOS Universidad Torcuato Di Tella

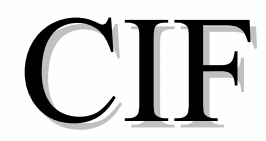

Centro de Investigación en Finanzas

Documento de Trabajo 01/2006

\title{
International Financial Integration through the Law of One Price
}

\author{
Eduardo Levy Yeyati \\ UTDT and IADB \\ Sergio L. Schmukler \\ World Bank \\ and \\ Neeltje Van Horen \\ World Bank
}




\title{
International Financial Integration through the Law of One Price
}

\author{
Eduardo Levy Yeyati Sergio L. Schmukler Neeltje Van Horen*
}

\begin{abstract}
This paper argues that the cross-market premium (the ratio between the domestic and the international market price of cross-listed stocks) provides a valuable measure of international financial integration, reflecting accurately the factors that segment markets and inhibit price arbitrage. Applying to equity markets recent methodological developments in the purchasing power parity (PPP) literature, we show that non-linear Threshold Autoregressive (TAR) models properly capture the behavior of the crossmarket premium. The estimates reveal the presence of narrow non-arbitrage bands and indicate that price differences outside these bands are rapidly arbitraged away, much faster than what has been documented for good markets. Moreover, we find that financial integration increases with market liquidity. Capital controls, when binding, contribute to segment financial markets by widening the non-arbitrage bands and making price disparities more persistent. Crisis episodes are associated with higher volatility, rather than by more persistent deviations from the law of one price.
\end{abstract}

JEL Classification Codes: F30; F36; G15

Keywords: capital market integration; market segmentation; TAR; PPP; capital controls; crisis

World Bank Policy Research Working Paper 3897, April 2006

The Policy Research Working Paper Series disseminates the findings of work in progress to encourage the exchange of ideas about development issues. An objective of the series is to get the findings out quickly, even if the presentations are less than fully polished. The papers carry the names of the authors and should be cited accordingly. The findings, interpretations, and conclusions expressed in this paper are entirely those of the authors. They do not necessarily represent the view of the World Bank, its Executive Directors, or the countries they represent. Policy Research Working Papers are available online at http://econ.worldbank.org.

* Levy Yeyati is with Universidad Torcuato di Tella and the Inter-American Development Bank. Schmukler and Van Horen are with the World Bank. This paper was finished while Schmukler was visiting the IMF Research Department. We are grateful to Stijn Claessens, Woochan Kim, Franc Klaassen, Dick van Dijk, and participants at presentations held at the European Economic Association 2005 Annual Meetings (Amsterdam), the Latin American and Caribbean Economic Association 2005 Annual Meetings (Paris), and the World Bank Macro Research BBL for helpful comments.

Email addresses: ely@utdt.edu, sschmukler@worldbank.org, and nvanhoren@worldbank.org. 


\section{Introduction}

In a context of growing globalization, the degree of effective integration of individual countries with the world economy is a topic that continues to receive extensive attention. This subject has already spawned a large body of empirical research attempting to gauge the extent of international integration and the factors that affect it. In this paper, we propose and study a new measure of international financial integration, where the latter is defined according to the law of one price (LOOP). This law stipulates that two markets are integrated when identical goods or assets are priced identically across borders.

Recently, this line of research has been particularly active in association with the literature on purchasing power parity (PPP), which examines whether LOOP holds in goods markets. This literature has provided two potentially important methodological findings. First, aggregation matters. In fact, Imbs, Mumtaz, Ravn, and Rey (2005) argue that previous empirical work on real effective exchange rates significantly understates the persistence of price deviations from PPP due to the presence of an aggregation bias, a finding that highlights the need to test convergence to PPP based on the prices of single (identical) products. Second, non-linearities matter. In this respect, Obstfeld and Taylor (1997) document the presence of non-linearities in the convergence process of international prices using threshold autoregressive (TAR) models. In related work based on single-good price comparisons, Imbs, Mumtaz, Ravn, and Rey (2003) show that this non-linearity in the data leads to understate the convergence speed when estimated using linear models (the more so the wider the no-arbitrage bands).

In this paper, we measure international financial integration through the lens of LOOP, in line with the recent developments in the PPP literature. To do so, we analyze the percentage price difference displayed by depositary receipts in international markets and their underlying shares in domestic markets (henceforth, the cross-market premium), controlling and testing for the presence of non-linearities. Since the depositary receipt and the underlying asset are two identical assets traded in two different markets, the behavior of the cross-market premium provides a powerful price-based measure of integration. If there are no restrictions to trading, the possibility of arbitrage implies that the prices of these assets should be equal, after adjusting for the exchange rate and transaction costs. It follows that, in a fully integrated market, the cross-market premium should be 
approximately zero. How well integrated are financial markets according to this measure? How does financial market integration compare to goods market integration? How does the cross-market premium reflect the presence of barriers that segment capital markets, delaying or inhibiting price convergence? These are the questions studied in this paper. ${ }^{1}$

The literature on price-based measures of international financial integration can be broadly divided into two strands. ${ }^{2}$ A first one analyzes integration by estimating return correlations across markets. Although very useful to understand the scope for international risk diversification, this work is typically based on a comparison of price indexes and as such is subject to the aggregation bias mentioned above. In addition, the results might be influenced by the different composition of indexes across countries. Furthermore, when based on capital asset-pricing models these studies test simultaneously the extent of integration as well as the applicability of a particular model. ${ }^{3}$ A second strand studies financial integration by testing LOOP in capital markets in various ways. ${ }^{4}$ Flood and Rose (2005b), for instance, estimate expected intertemporal marginal rates of substitution for different markets, which they then compare to test for (domestic and international) asset market integration. Another group of papers, in response to the composition problem associated with price indexes, specifically focuses on the evolution of the premium of emerging market closed-end country funds over the value of the underlying portfolio. ${ }^{5}$ While free from the composition bias, these attempts fall short of comparing identical assets, as the restrictions and management of closed-end

\footnotetext{
${ }^{1}$ Note that the cross-market premium is not a measure of capital mobility. In a world of perfect capital mobility, effective integration (price convergence) would still be affected by the intensity of transaction costs.

${ }^{2}$ In addition to price-based measures, stock-based measures of financial integration have spawned a large body of empirical work. A thorough survey of the vast literature on financial integration far exceeds the scope of this paper. A comprehensive overview of the main operational measures of financial integration is provided by Obstfeld and Taylor (2002) and Prasad, Rogoff, Wei, and Kose (2003), among others.

${ }^{3}$ Studies based on stock market indexes include, among many others, Cashin, Kumar, and McDermott (1995), Soydemir (2000), Masih and Masih (2001), Scheicher (2001), and Chen, Firth, and Rui (2002). Capital asset-pricing models to test for market integration have been applied by Bekaert and Harvey (1995), Bekaert, Harvey, and Ng (2005), Flood and Rose (2005a), and Carrieri, Errunza, and Hogan (2006), among others.

${ }^{4}$ Criteria such as the (covered and uncovered) interest rate parity, and the real interest rate parity conditions, are related to this group to the extent that they focus on the analysis of onshore-offshore return differentials (see, among many others, Meese and Rogoff 1988, MacDonald and Nagayasu 2000, and Chortareas and Driver 2001). Strictly speaking, however, these conditions are not LOOP tests, as they abstract from the potentially relevant role played by exchange rate risk.

${ }^{5}$ See Frankel and Schmukler (1998 and 2000) and Levy Yeyati and Uribe (2000).
} 
funds distinguishes them from their underlying portfolio. Alternatively, Froot and Dabora (1999) examine the price behavior of pairs of stocks of large Siamese twins (corporates that pool cashflows and fix their distribution) traded in different countries, and find that prices deviations of these "nearly identical" stocks are habitat dependent.

The cross-market premium proposed here offers a number of advantages as a measure of financial integration. First, it allows testing LOOP based on two truly identical assets, avoiding the composition and aggregation biases, as well as the need to control for idiosyncratic risk. ${ }^{6}$ Second, because it is a market-based measure, no model needs to be imposed on the data. Third, the measure is continuous and spans the range between complete segmentation and complete integration, capturing variations in the degree of integration that can arise, for example, from the introduction or lifting of investment barriers. Fourth, it is amenable to the use of TAR models, which capture nonlinearities in the data and estimate the width of no-arbitrage bands, a good indicator of financial integration. ${ }^{7}$

Extending the work on PPP to financial integration is a natural choice for at least two reasons. First, the analogy between real and financial markets interaction is apparent, as they both ultimately entail a test of LOOP. As such, TAR models are as natural a way to test for the presence of transaction costs-based segmentation in financial markets as they are for international good markets. ${ }^{8}$ Second, the use of TAR models allows us to relate and compare our findings on asset markets with those reported by the PPP literature on good markets. To the extent that (i) depositary receipts and the underlying shares are identical assets (more so than most pairs of similar goods analyzed by the PPP literature) and that (ii) transaction costs are smaller in financial markets than in good markets, one would expect to find smaller and less persistent price disparities.

\footnotetext{
${ }^{6}$ Depositary receipts do not involve two different issues by the same company but, rather, claims on the same stock of shares traded in the local market.

${ }^{7}$ Return differentials between ADRs and the underlying shares in emerging economies have received increasing attention recently. See, for example, Alaganar and Bhar (2001) and Gagnon and Karolyi (2004).

${ }^{8}$ The view that a minimum return differential is required to induce arbitrage (hence, the non-linearities in cross-market premia) dates back, at least, to the work of Einzig (1937, p. 25). Einzig's point has been empirically tested by Peel and Taylor (2002), who apply the TAR methodology to the weekly dollarsterling covered return differentials during the interwar period. Obstfeld and Taylor (2002) replicate the exercise using monthly data.
} 
For our empirical estimations, we analyze systematically the distribution of daily cross-market premia from 1990 to 2004, for a large set of stocks from different countries. In choosing the sample, we are constrained in at least two ways. First, many cross-listed stocks are highly illiquid, often exhibiting infrequent trading. Including those stocks would substantially alter the behavior of the premium and the reliability of the results. Second, TAR models constrain us to work with firms that have a relatively long history of trading data. Finally, we are particularly interested in countries that experienced crises and/or the imposition of capital controls, to evaluate whether financial integration is affected in those instances. Once we take these considerations into account, we are able to use 76 firms from nine emerging economies, Argentina, Brazil, Chile, Indonesia, Korea (South), Mexico, Russia, South Africa, and Venezuela. In all cases, we study the integration of these emerging economies with the U.S.

Methodologically, we calibrate a TAR model to estimate no-arbitrage bands (that is, zones where deviations between depositary receipt and stock prices are not arbitraged away) and convergence speeds outside the band. As in the PPP literature, we interpret both the band width and the convergence speed as (inverse) measures of integration. In all cases, we also estimate autoregressive (AR) models as a benchmark to test the consistency of the TAR specification. We then study how the TAR and AR estimations differ with stock liquidity (as measured by the trading volume), the introduction of capital controls (explicitly intended to segment markets), and financial crises (arguably, situations where market segmentation is most likely to arise). ${ }^{9}$

The main results of this paper are the following. First, we find evidence of strong financial integration: the cross-market premium remains close to zero, with very narrow no-arbitrage bands and rapid convergence to zero outside the bands. Second, there is evidence of non-linearities in the behavior of the premium. Moreover, convergence speeds are slower when estimated by an AR model, and the difference with respect to the speed estimated by the TAR model is proportional to the band width, as expected. Third,

${ }^{9}$ Depositary receipts have been used recently to assess the impact of capital controls and crises. Rabinovitch, Silva, and Susmel (2003) attribute the persistence of return differentials between ADRs and stocks in Chile to the presence of controls. Melvin (2003) and Auguste, Dominguez, Kamil, and Tesar (2006) examine the large ADR discounts that built in the midst of the Argentine crisis in early 2002, which Levy Yeyati, Schmukler, and Van Horen (2003) interpret as a reflection of the strict controls on capital outflows and foreign exchange transactions imposed at the time. We explore this hypothesis in more depth here. Pasquariello (2006) presents evidence of large return differentials during crises. 
liquidity deepens financial integration: no-arbitrage bands are narrower and convergence is more rapid, the more liquid a stock is. Fourth, deviations from LOOP are far smaller and less persistent (even for illiquid stocks) than those reported in the literature on goods markets, reflecting the lower transaction costs in financial markets. Fifth, the presence of controls is directly reflected in the intensity of integration, in the form of wider bands and more persistent deviations (less rapid convergence when outside the band), except where controls are not binding. Finally, by contrast, crisis episodes are associated with greater volatility, but not with a higher persistence of the deviations from LOOP. However, since the limited length of crisis periods prevents the use of TAR models, this result has to be subject to further testing once more data become available.

In sum, the cross-market premium explored here appears to be a good gauge of the degree of international financial market integration, reflecting accurately the factors that segment markets. On the one hand, the measure detects the presence of nonlinearities in the evolution of the premium, in line with the hypothesis of a no-arbitrage band due to transaction costs. On the other, it confirms our priors that (binding) capital controls tend to weaken cross-market arbitrage, allowing for wider and more persistent deviations from LOOP. The results on crises leave some interesting questions for future research.

The remainder of the paper is organized as follows. Section 2 discusses the link between the cross-market premium and financial integration. Sections 3 and 4 discuss the data and methodology. Section 5 characterizes the behavior of the cross-market premium, compares financial market integration with goods market integration, and studies how the premium is related to liquidity. Section 6 examines how capital controls and crises affect financial integration and to what degree the cross-market premium is a good measure of integration. Section 7 offers some concluding remarks.

\section{The Cross-Market Premium}

The cross-market premium is defined as the percentage difference between the dollar price of the stock in the domestic market and the price of the corresponding depositary receipt (DR). Depositary receipts (also known as American Depositary Receipts or ADRs) are shares of non-U.S. corporations traded in the U.S. (and denominated in 
dollars), while the underlying shares trade in the domestic market of the issuer. A depositary receipt represents a specific number of underlying shares remaining on deposit in a so-called custodian bank in the issuer's home market. A new DR can be created by depositing the required number of shares in the custodial account in the market. The dividends and other payments will be converted by this bank into U.S. dollars and provided to the holders in the U.S. The process can simply be reversed by canceling or redeeming the DR. In this way, an underlying stock can easily be transformed into a DR and vice versa.

The cross-market premium (or discount) thus reflects the deviation between the home market price of the stock and its price in New York. It can be computed by converting the local currency price of the underlying stock in dollar prices, multiplying this by the number of underlying shares one DR represents, and then dividing their value by the DR price. Or,

$$
\pi_{t}=\frac{S_{t} r P_{t}^{\text {und }}-P_{t}^{d r}}{P_{t}^{d r}}
$$

with $\pi_{t}$ representing the premium at time $t, S_{t}$ the spot exchange rate expressed in U.S. dollars per local currency, $r$ the number of underlying stocks per unit of DR, $P_{t}^{\text {und }}$ the price of the underlying stock in local currency, and $P_{t}^{d r}$ the price of the DR in New York in U.S. dollars.

When the domestic market is fully integrated with the U.S. market, transaction costs are zero and the two markets close at the same time, arbitrage should be instantaneous and costless. If the return of the underlying stock is higher than the return of the DR, investors can make an instant profit by buying the DR, transforming it into the underlying stock and selling this stock. This will drive the price of the underlying stock down and the premium back to zero. The reverse story holds when the return of the DR is higher. In principle, the premium will be equal to zero. If a shock occurs too late during the day to be arbitraged away, closing prices will differ, but this difference will disappear quickly the next trading day. ${ }^{10}$

\footnotetext{
${ }^{10}$ The same should apply to temporary non-zero premia due to differences in trading hours between the domestic and the U.S. stock market.
} 
In reality, however, there does not exist instantaneous and costless arbitrage. If an investor decides to transform underlying stocks into DRs and sell them in the U.S., he has to incur transaction costs. These typically include a broker's fee and transaction fee to buy the underlying stock and transform it into the DR, plus a second broker's fee to sell the DR. Additional transaction costs might be the cost of opening a bank account in the U.S. or a tax that needs to be paid to transfer the funds back to the domestic market. A U.S. investor would face similar transaction costs. Furthermore, since settlement in equity markets typically takes place a number of days after the transaction, there is also a foreign exchange risk unless the stock trade is matched with a forward exchange rate contract. In turn, these transaction costs can generate a "no-arbitrage band" within which price deviations are not large enough to induce arbitrage. Higher transaction costs induce the widening of the no-arbitrage band and, thus, weaker integration.

\section{Data}

To select our sample of stocks we use the following criteria. First, the countries used in the paper had to experience the introduction (or lifting) of capital controls and/or one or more financial crises during the sample period. Second, the selected stocks need to exhibit a long history of DR listings with important trading volume. For this reason, we restrict our attention to stocks that are publicly traded in the United States, either on the NASDAQ or the New York Stock Exchange (NYSE), ${ }^{11}$ and that exhibit a minimum liquidity. More precisely, we exclude a stock if: (i) the number of days in which both the stock and its DR traded over the preceding 365 days is below 200 (in addition, for qualifying stocks we exclude the observations corresponding to dates when no trading took place); ${ }^{12}$ (ii) shows large changes in the trading volume pattern; ${ }^{13}$ (ii) shows irregular behavior (e.g., significantly different means in sub-periods); or (iv) has less than two years of observations. ${ }^{14}$

\footnotetext{
${ }^{11}$ These are so-called level 2 and level 3 ADRs.

${ }^{12}$ Note that in almost all cases, firms trade either almost every day (about 250 days per year) or very infrequently (much less than 200 days), and are therefore excluded.

${ }^{13}$ As we show below, the behavior of the premium depends significantly on the liquidity of the stock as measured by its trading volume.

${ }^{14}$ The last two conditions are crucial for a reliable estimation of stock-by-stock TAR models.
} 
The liquidity criterion (i) is of particular importance in our case, given that many DRs from emerging economies display infrequent trading. This, in turn, would invalidate the use of the cross-market premium, since it would reflect spurious price divergences due to the lack of transactions. Since price quotes correspond to the latest trade, quotes recorded at different dates may not represent a price divergence but rather the evolution of prices over time. Appendix I discusses more extensively how trading frequency affects the behavior of the cross-market premium.

These restrictive selection criteria seem necessary for a meaningful analysis, but also reduce substantially the number and type of candidate countries and stocks. We work with 76 stocks (out of 133 DRs that trade in the NYSE of the NASDAQ) from nine emerging economies: Argentina (8 stocks), Brazil (24), Chile (12), Indonesia (2), Mexico (13), South Africa (7), Korea (6), Russia (2), and Venezuela (2). Appendix Table 1 reports the companies that are included in the respective portfolios and the period for which the premium is calculated.

The data needed to calculate the premium (the dollar price of the stock in the domestic market, the price of the DR in New York, and the number of underlying shares per unit of the depository receipt) come from Bloomberg. For Argentina, Brazil, Chile, and Venezuela we use the closing price both in the domestic market and in New York. For Asian markets, which are already closed when New York opens, as well as for Russia and South Africa, we use instead the closing price (and the exchange rate) in the domestic market and the opening price in New York, to keep distortions due to time differences to a minimum.

\section{Methodology}

As noted, we expect higher transaction costs to lead to broader bands of no-arbitrage. To the extent that high transaction costs are associated with a lower level of financial integration, the estimated width of the no-arbitrage bands provides a measure of effective integration.

The existence of transaction costs basically implies that two different regimes exist, an arbitrage and a no-arbitrage regime. If, on the one hand, the difference between the two prices is smaller than the transaction costs, arbitrage will not take place and the 
difference can persist. However, when a shock in either of the two markets results in a difference between the two prices that exceeds the transaction costs (that is, the premium is outside the no-arbitrage band), it will trigger profitable arbitrage trades that would elicit a strong pressure on the premium to revert to inside the band. ${ }^{15}$ In other words, theoretically there will be a no-arbitrage regime, where the persistence is high, and an arbitrage regime, where there exists pressure on prices to converge.

The implication of the presence of transaction costs as a cause for the existence of two regimes in the data has been mostly developed by the purchasing power parity literature. For example Sercu, Uppal, and Van Hulle (1995) and Michael, Nobay, and Peel (1997) have analyzed real exchange rates and developed a theory suggesting that the larger the deviation from PPP, the stronger the tendency for real exchange rates to move back to equilibrium.

As mentioned in the Introduction, while a number of studies have recently applied TAR models to estimate no-arbitrage bands for the case of real exchange rates, applications to financial data are far more limited. ${ }^{16}$ However, TAR is a natural choice to model the type of regime changes that we expect to be prevalent in the DR market, as it assumes a discrete change in the AR process once a certain threshold is crossed.

TAR was first proposed by Tong (1978) and further developed by Tong and Lim (1980) and Tong (1983). Its main premise is to describe the data-generating process by a piecewise linear autoregressive model: a TAR model works by estimating regime switching parameters as a function of the distance of an observation from the mean.

As we expect, a reversion back to the band and not back to the mean once outside the no-arbitrage regime, we estimate a so-called Band-TAR model first used by Obstfeld and Taylor (1997), to which we introduce two modifications. First, we correct for the presence of serial autocorrelation using a Band-TAR adaptation of the augmented

\footnotetext{
${ }^{15}$ Note that the premium would gradually decline in absolute value but would not necessarily revert to zero, as arbitrage ceases as soon as the premium is within the band.

16 A notable exception is, for example, Rabinovitch et al. (2003), who use the TAR model as an approximation for the arbitrage adjustment mechanism between the local and ADR markets for Argentine and Chilean stocks. Another one is Canjels, Prakash-Canjels, and Taylor (2004), who use a TAR model to study the efficiency of the dollar-sterling gold standard and provide insights into the evolution of market integration in the classical gold standard. In addition, several studies have applied TAR models to study the behavior of interest rates (Balke and Wohar 1998, Mancuso, Goodwin, and Grennes 2003, Juhl, Miles, and Weidenmier 2006, among others).
} 
Dickey-Fuller test. Second, the residuals are corrected for GARCH effects to account for the heteroskedasticity prevalent in the data.

The resulting specification is the following:

$$
\begin{aligned}
& \Delta x_{t}=\left(I_{\text {in }}\right) \beta_{\text {in }} x_{t-1}+\left(I_{\text {out }}\right) \beta_{\text {out }} \Phi\left(x_{t-1}, c\right)+\sum_{j=1}^{k} \phi_{j} \Delta x_{t-j}+\varepsilon_{t}, \\
& \sigma_{t}^{2}=\alpha_{0}+\sum_{j=1}^{p} \alpha_{j} \varepsilon_{t-j}^{2}+\sum_{j=1}^{q} \lambda_{j} \sigma_{t-j}^{2}, \\
& \Phi\left(x_{t-1}, c^{u p}\right)=x_{t-1}-c^{u p} \text { if } x_{t-1}>c^{u p}, \\
& \Phi\left(x_{t-1}, c^{\text {low }}\right)=x_{t-1}+c^{\text {low }} \text { if } x_{t-1}<c^{\text {low }}, \\
& c^{\text {up }}>0 \text { and } c^{\text {low }}<0, \\
& I_{\text {out }}=1 \text { if } x_{t-1}>c^{\text {up }} \text { or } x_{t-1}<c^{\text {low }} \text {; zero otherwise, } \\
& I_{\text {in }}=1 \text { if } c^{\text {low }}<x_{t-1}<c^{\text {up }} \text {; zero otherwise. }
\end{aligned}
$$

This model is known as the $\operatorname{TAR}(k, 2, d)$, where $k$ reflects the arbitrary autoregressive length, 2 the number of thresholds (which, a priori, we set at 2), and $d$ the arbitrary delay parameter (also called the threshold lag). We assume that the thresholds are symmetric and that the dynamics of the process outside the threshold are the same regardless of whether there exists a premium or a discount. Furthermore, we set $d$ equal to one. $\beta_{\text {in }}$ and $\beta_{\text {out }}$ reflect the convergence speed in the no-arbitrage and arbitrage regimes, respectively. We assume that the constants in both regimes are zero. For each country, we estimate a different model, where $k, p$, and $q$ are set in such way that the residuals do not contain any serial correlation or heteroskedasticity up to lag 10 .

The model is estimated following the procedure described in Obstfeld and Taylor (1997). The estimation proceeds via a grid search on the threshold, which maximizes the $\log$ likelihood ratio $L L R=2(L a-L n)$. This implies that, for every given threshold, the maximum likelihood estimation of the TAR model amounts to an OLS estimation on partitioned samples, i.e. sets of observations with $x_{t-1}$ either inside or outside the thresholds.

$L a$ refers to the likelihood function of the above TAR model: ${ }^{17}$

\footnotetext{
${ }^{17}$ Note that in our model we implicitly assume that the residuals are the same in both regimes. As a result, we can estimate the LLR of the TAR the same way as the LLR of the AR model and do not need to divide the likelihood function in two parts, one using the residuals of the inner and another one using the residuals of the outer regime, as done by Obstfeld and Taylor (1997). In fact, using this partitioned likelihood
} 


$$
L a=-\sum_{t} \frac{1}{2}\left(\log (2 \pi)+\log \left(\sigma^{2}\right)+\varepsilon_{t}^{2}\right) / \sigma^{2} .
$$

The Null is an AR(1) model and Ln is its likelihood function similar to La.

As the threshold is not defined under the null, standard inference is invalid and LLR does not follow the usual $\chi^{2}$ distribution. To derive the critical values of the LR test, we follow Obstfeld and Taylor and use Monte Carlo simulations. First, the AR(p) null model is estimated on the actual data $\left(x_{1}, \ldots . ., x_{T}\right)$. Then, 600 simulations of the model are generated. Each starts at $x_{-b}=0$ and ends at $x_{T}$. To avoid initial value bias, the first b values are discarded (we set b at 50). For each simulation, the TAR model is estimated as outlined above and the simulated LLR is calculated. The empirical distribution of the LLR can then be calculated from the 600 simulations, and this is used as the basis for the inference in judging the alternative TAR model against the AR null.

It is important to make clear that the significance test described above has the important limitation of low power. As shown by Johansson (2001), the probability that the TAR model is mistakenly rejected is high. The method introduced by Hansen (1997) and used, for example, by Imbs et al. (2003) is based on a Wald statistic and is not useful for our purpose as heteroskedasticity in our data is strong (as is common for high frequency financial data). As a result, our best approach is to use the test described above, but to take a rejection of the TAR model with caution. Nonetheless, for robustness, we run all our estimations using a simple AR model as well, to verify that the conclusions are not model-dependent.

\section{The Cross-Market Premium and Financial Integration}

In this section, we study the behavior of the cross-market premium during "tranquil" times, in the absence of capital controls. For ease of exposition, we leave a detailed account of the definition of crisis periods for Section 6, where the incidence of crisis on integration is examined. Table 1 presents a first glance at the data, where we show the summary statistics of the simple average of the cross-market premium of the stocks in

function increases the likelihood of rejecting the AR model in favor of the TAR model when residuals are not normally distributed. 
each country's portfolio. ${ }^{18}$ A positive premium implies that the price of the underlying stock is higher than the DR price. The table shows that the average premium is close to zero in all cases. For the pooled data, the mean premium is 0.15 percent, with a standard deviation of 1.65. The largest average premium is in Korea, with 1.59 percent; in all other cases, this number is below 1 percent.

\subsection{AR and TAR Estimates}

In order to compare financial market integration with goods market integration, we estimate a TAR model for the most liquid stock in each country during tranquil periods. As a measure of liquidity, we use the average of the value traded for both the underlying stock and the DR during the period under study.

We next estimate the TAR model using a grid-search on the threshold, as described in Section 4. In Table 2, we provide a summary of our findings on the thresholds and the convergence speed outside the no-arbitrage band. For each stock, we show the optimal threshold and the log likelihood ratio of the estimated TAR model relative to the AR model. In addition, for this threshold, we show the implied half-life associated with $\beta_{\text {out }}$. For comparison, we also show the implied half-life for the standard AR model.

The results confirm our priors. Bands of no-arbitrage range from 0.05 percent in South Africa to 0.18 percent in Mexico. This implies, in particular, that the cross-market premium can, in the case of Mexico, move between -0.18 and 0.18 without arbitrage taking place in the market. ${ }^{19}$ Once outside the inaction-band, arbitrage takes place very rapidly: the typical half-life is less than a day. Estimating the TAR model by pooling all stocks yields a tight no-arbitrage band of 0.02 percent, even narrower than the average band estimated country by country. ${ }^{20}$

For brevity, not all estimated parameters were included in Table 2. However, we find that, as expected, in almost all cases $\beta_{\text {in }}$ is not significantly different from zero,

\footnotetext{
${ }^{18}$ Results for individual stocks in our sample are reported in Appendix Table 2.

${ }^{19}$ Note that these results do not imply that South Africa is more integrated with the U.S. than Mexico. As we show in the next section, deviations from the law of one price are affected by the liquidity of the stock.

${ }^{20}$ These results should be taken as indicative, since pooling observations with different thresholds and halflives may bias the results.
} 
implying that inside the band of no-arbitrage the premium follows a random walk. Furthermore, the estimated sum of the ARCH and GARCH parameters lies between 0.90 and 0.99 , with a value of 0.95 for the majority of stocks.

Having computed the TAR models, we can compare the estimates obtained in financial markets with those previously found in goods markets. To do so, we use the results reported in Obstfeld and Taylor (1997), who estimate a similar model for Mexico, South Africa, and a number of developed countries. ${ }^{21}$ Comparing their results (reported at the bottom of Table 2) with ours shows that, as expected, the band of inaction is larger in their case. Furthermore, arbitrage takes place much more rapidly in financial markets than in goods market. While the typical half-life as estimated by the TAR model is less than a day in financial markets, it can be more than a year in goods market. Similar results can be found when the half-life is based on the AR model.

If non-linearities are present in the evolution of the cross-market premium, convergence speeds should be slower when estimated by a linear (AR) model than those obtained from the TAR model, as is indeed the case for each of the stocks in the table. Moreover, the wider the band-width, the higher the persistence estimated by the linear model, as Figure 1 shows. Additionally, the difference between the half-life estimated by the AR, and that obtained from TAR models outside the band, is itself proportional to the linear half-life. These results, which provide further evidence of how the presence of nonlinearities influences the results from a linear estimation, are consistent with similar tests reported by Imbs et al. (2003) for goods markets.

One could argue that the rapid arbitrage we find is related to the fact that these results are based on the most liquid stocks in the sample for each country. However, while liquidity certainly plays a role in the degree of integration, the previous conclusions carry through to more illiquid stocks, as we show in the next section.

\footnotetext{
${ }^{21}$ Obstfeld and Taylor (1997) consider disaggregated as well as aggregated consumer price indexes (CPIs) for a number of U.S. cities and a number of, mostly, developed countries at a monthly frequency during 1980-1995. The results reproduced in Table 2 refer to their results for the aggregated CPIs.
} 


\subsection{Integration and Liquidity}

One would expect the bands of no-arbitrage to widen as liquidity declines, to the extent that investors incorporate a liquidity risk premium as an additional transaction costs. ${ }^{22}$ To see whether this is indeed the case, we examine how the band-width is associated with the liquidity of the stock. Specifically, we estimate - again, for tranquil periods without capital controls - a TAR model for each individual stock in our sample, and then regress the estimated thresholds against the liquidity of the stock. Liquidity, in turn, is measured as the log of the average of the mean value traded of the underlying stock and the DR, both computed over the same period used for the TAR. ${ }^{23}$ In addition, we investigate whether arbitrage outside the band takes place more quickly as liquidity increases. Finally, as a robustness check, we also regress the half-lives estimated by the AR model which, as noted, are proportional to the band-width - on the stock liquidity. In all regressions, we control for country-specific fixed effects. ${ }^{24}$

Figure 2 reports the regression results and the partial regression plots, revealing the presence of a significant negative correlation between band-width and liquidity. Furthermore, the figure shows that band reversion, once outside the no-arbitrage regime, takes place more slowly (half-lives are longer) for illiquid stocks. The same is true for the linear model: illiquid stocks are associated with more persistence price deviations. ${ }^{25} \mathrm{In}$ sum, the size and persistence of the deviations from LOOP appear to be higher (integration appears to be weaker) as the liquidity of the stock declines: illiquidity adds to transaction costs and weakens financial integration.

\footnotetext{
${ }^{22}$ Note that transaction costs are likely to be non-linear (e.g., large transactions command proportionally smaller fees). However, there is a priori no reason to expect that the average trade size of illiquid stocks should be smaller than that of more liquid stocks - if they were, this would add to the liquidity premium.

${ }^{23}$ See Levine and Schmukler (2006) for alternative measures of liquidity and their close relation with value traded.

${ }^{24}$ TAR and AR estimates for all the individual stocks in our sample are reported in Appendix Table 2. Note that in the case of Korea estimates are only available for two stocks. As explained in the next section, this is caused by the fact that the remaining four stocks in the portfolio were subject to capital controls over the entire sample period.

${ }^{25}$ Measuring liquidity only by the mean value traded of the underlying stock or the mean value traded of the DR does not alter the result.
} 


\section{Time-Varying Financial Integration: Capital Controls and Crises}

The imposition of capital controls increases transaction costs and tends to break down LOOP. For this reason, capital controls provide a natural test of the cross-market premium as a measure of the intensity of financial integration. On the other hand, to the extent that various sources of risk increase during crises, one can expect prices to diverge more markedly during a crisis period. This section centers on how the behavior of the cross-market premium differs in these two particular situations.

\subsection{Crises, Controls, and the Cross-Market Premium}

In the presence of controls on capital outflows, an international investor seeking to buy the DR to sell the underlying stock would need to repatriate the proceeds from this sale and incur a cost $\kappa$. Conversely, when controls on inflows are in effect, purchasing the underlying stock to sell the DR would require paying an inflow cost $\lambda$.

Thus, as quantitative controls on outflows increase in effective intensity ( $\kappa \rightarrow \infty$ ), the potential deviation of local stock prices relative to DRs increases proportionally: binding controls on outflows would elicit a large cross-market premium. Similarly, controls on inflows would introduce a negative cross-market premium, as they inhibit international investors to profit from relatively low domestic prices. In sum, controls on outflows (inflows) increase the upper (lower) boundary of the no-arbitrage band, keeping the other boundary unchanged, and causing the premium to be, on average, positive (negative).

The impact of a financial crisis is more ambiguous. It can temporarily influence the level of financial integration, as the risk associated with swapping the underlying stock for the DR and vice versa increases, due to higher exchange rate volatility, as well as transfer and convertibility risk. On the other hand, an increase in the variability of the premium could simply reflect the greater price volatility that characterizes episodes of financial turmoil, even if the degree of arbitrage remains unaltered. 


\subsection{Crises and Controls: What and When?}

Before turning to the behavior of the premium in these two particular situations, it is important to define what we understand by capital controls and financial crises, and how we identify the periods when they are in place.

Capital controls periods are relatively easy to detect. Governments impose them through regulation. Moreover, a number of public institutions document them. Appendix Table 3 describes the capital controls imposed in each of the countries that we study. One salient feature from this table is that capital controls differ by intensity, across countries and over time. Another relevant aspect is the difference in the type of control, the most notorious one being between controls on inflows (typically used to discourage short-term flows) and those on outflows (to prevent the capital flight in the midst of a crisis). We focus our attention solely on controls that may affect the cross-market premium.

Six countries in our sample experienced a period when capital restrictions affected the behavior of stock market: Argentina, Chile, Indonesia, Korea, South Africa, and Venezuela. In Argentina, controls on capital outflows were introduced in December 2001 together with restrictions on cash withdrawals from commercial banks (the so called “corralito”) as an attempt to stop the capital flight. The majority of these controls stayed in place until December 2002, when the corralito was lifted and the bulk of the restrictions were eliminated. However, in the first months after the corralito was abandoned, some minor controls were still in place that could potentially have affected the premium. From June 2003 onwards, virtually all controls were eliminated. Chile introduced controls on inflows in the form of an Unremunerated Reserve Requirement (URR) already in 1992, but these controls only affected the DR market from July 1995 onwards. In August 1998, with the markets in turmoil and the Chilean peso under attack, the controls were finally lifted. ${ }^{26}$

Controls in South-East Asia took a different form, typically involving quantitative limits on foreign ownership. Indonesia had a 50 percent limit on foreign investments in place, when the first DR started trading; this restriction was lifted in September 1997. Also in Korea, a ceiling on the share of foreign investor ownership was in effect. For

\footnotetext{
${ }^{26}$ In fact, the URR was set to zero, but the mechanism was left in place until it was finally eliminated in 2002.
} 
most stocks, this ceiling was lifted in May 1998; however, for a number of stocks it is still in place today. Cross-listed stocks using DRs faced an additional restriction: until January 1999, the conversion of underlying shares in DRs was severely restricted (e.g. approval was needed by the issuing company's board). In November 2000, Korea changed its regulations so that underlying shares could be converted to DRs without board approval as long as "the number of underlying shares that can be converted into DRs" is less than "the number of underlying shares that have been converted from DRs." ${ }^{27}$ For four of the stocks in our country portfolio (SK Telecom, Kepco, Posco, and KT Corp) this rule has often prevented arbitrage to take place: in effect, these stocks still face controls on capital inflows. The other two stocks in our portfolio (Kookmin Bank and Hanaro Telecom), however, were unaffected by the rule during the period covered by our sample, so that controls were not effectively in place. To accommodate for this difference in the incidence of controls, we divide Korean stocks into two groups: restricted and unrestricted. Furthermore, we divide the control period of Korea into three distinct subperiods. The first one, referred to as very restrictive, lasts until January 1999. The second period, called restrictive, lasts from January 1999 until November 2000, when free conversion was allowed but conditioned by the rule. The third period, less restrictive, goes from November 2000 to the end of the sample period.

In South Africa, the dual exchange rate system adopted in 1979, and temporarily abandoned in 1983, effectively worked as a control on capital outflows. This system was abolished in March 1995. Venezuela experienced two episodes of controls on capital outflows. The first one started in June 1994 and lasted until May 1996. A new set of controls on outflows was introduced in January 2003, and remain in place at the end of our sample period.

Crisis times are much more difficult to pin down. Perhaps what makes this task particularly challenging is the lack of an uncontroversial operational definition of crisis. The literature has applied different methodologies using various ad-hoc criteria to identify crises. For our purpose, it is essential to determine accurately the beginning and the end of the crisis. To do so, we follow the approach adopted by Broner, Lorenzoni, and Schmukler (2004) and use the exchange market pressure (EMP), computed as the

\footnotetext{
${ }^{27}$ See the Financial Supervisory Service's Regulation on Supervision of Securities Business, Article 7-9.
} 
weighted average of the daily changes in the interest rate and the log difference of the exchange rate, as a measure of financial distress. This approach allows us to distinguish country-specific crisis periods without resorting to the use of ex-post data. ${ }^{28}$

The crisis periods in the respective countries are determined as follows. First, we construct a series of EMP volatility, measured as the 15-day rolling standard deviations of the EMP. A crisis initiates when the EMP volatility exceeds a threshold level and remains above that level for at least four weeks, where the threshold is defined as the mean of the EMP volatility plus one standard deviation, computed for each country over the period covered by the sample. A crisis ends if the EMP volatility declines below the threshold and remains there for three months (in which case, the end date coincides with the date of the initial decline). The exchange and interest rate series come from Bloomberg and Datastream. The interest rates used vary according to data availability (in all cases, we verify that all available market-determined interest rates behave similarly over the sample period). ${ }^{29}$ Table 3 reports the crisis periods identified by our methodology. All non-crisis periods are called tranquil periods, and are the ones used in the previous section.

\subsection{Summary Statistics}

Figure 3 displays the evolution of the simple average of the cross-market premium of all stocks selected for each country. For the particular case of Korea, we include two graphs: one including stocks that have been subject to restrictions over the whole sample period, and one including only the unrestricted stocks. Light shaded areas indicate crisis periods, while darker shaded areas indicate control periods. Periods when crises coexist with controls (as is the case for Argentina, Chile, Korea, and Venezuela) are considered as control periods. Thus, in what follows, crisis periods specifically refer to periods of

\footnotetext{
${ }^{28}$ The weights are equal to the reciprocal of the standard deviation of the respective variables. Ideally, one would also like to include the change in reserves; unfortunately, these data are not available on a daily frequency for the countries in our sample. To define the crisis period, Broner et al. (2004) additionally use the 9-year bond spread, which is not readily available for all countries in our sample.

${ }^{29}$ The following rates were used: 7-day interbank rate (Argentina), the bank deposit certificate rate (Brazil), the 30-day CD rate (Chile, Venezuela), the interbank call money rate (Indonesia, Korea, Russia), the 90day bank deposit rate (Mexico), and the 3-month discount rate (South Africa).
} 
financial turmoil when capital controls are not in effect. ${ }^{30}$ Finally, the control period in Korea is divided into three sub-periods, to reflect the fact that the severity of restrictions lessened during the sample period as explained in the previous section.

Figure 3 shows that during tranquil periods the cross-market premium oscillates around zero. This appears to be case also at times of financial distress, characterized by a larger volatility of the premium. The average premium turns positive in periods when capital outflows are restricted (Argentina, South Africa, and Venezuela) and negative in periods of controls on inflows - except in Indonesia, where the (relatively loose) limits on foreign participation may have been not binding at the time and where domestic investors could still do the arbitrage. ${ }^{31}$ By contrast, in Korea, where a similar ceiling is combined with a rule restricting the convertibility of the DRs, arbitrage is impeded regardless of whether the ceiling is binding. The evidence that the discount is much lower in Chile than in Korea, on the other hand, directly reflects the different nature of the restrictions: quantitative limits that prevent arbitrage in Korea, and an implicit tax that weakens arbitrage in Chile. Note that the Chilean "tax" on inflows effectively increases the price of the underlying stock, which should therefore fluctuate around the average value of the tax from the investor's standpoint. According to the figure, that was roughly two percent.

Table 4 displays summary statistics of the average cross-market premium during tranquil, crisis, and control times. ${ }^{32}$ The table shows that the presence of controls is associated with sizeable premia of the expected sign, ranging from 49 percent under controls of outflows in Venezuela, to -31 during the period of most restrictive controls on inflows in Korea. The only exception is, again, Indonesia, where the small positive premium is associated with the presence of controls on inflows, consistent with accounts that the latter were not binding at the time.

In addition, a comparison with tranquil times shows that the volatility of the premium increases significantly both during crisis and under controls, as expected. In particular, the volatility and the mean of the average premium are positively correlated.

\footnotetext{
${ }^{30}$ Although the crisis in Argentina started before the controls were introduced, the sample period without controls (light-shaded in Figure 3) is so short that we do not consider it as a crisis period for the purpose of the empirical tests below.

${ }^{31}$ A ceiling on foreign investment will not affect arbitrage by foreign investors as long as foreign participation is well below the limit.

${ }^{32}$ For Korea, the statistics are derived from the average premium of the unrestricted stocks (tranquil period) and the average premium of the restricted stocks (control periods).
} 
Thus, the volatility is highest for control periods and, to a large extent, proportional to the premium generated by the controls, in line with the view that the latter induce a zone of inaction that allows for wider (and persistent) deviations from LOOP. In the following sections, we explore this preliminary evidence more closely.

\subsection{Integration in Control Periods}

When (binding) controls on capital outflows are introduced the premium can become positive as the upper band of no-arbitrage becomes larger, while the lower band is unaffected by the controls. In the case of controls on inflows, we expect to observe exactly the opposite.

For each stock in the portfolio that was traded during a period of controls, we estimate the TAR model in the following way. First, the model is estimated for the tranquil period. Next, a TAR model is estimated for the control period, setting the threshold of the no-arbitrage band that should not be affected by the introduction of the controls equal to the value estimated for the tranquil period, and estimating the remaining threshold. Thus, the impact of controls should be reflected in an asymmetric widening of the band.

In turn, for the AR model we expect the persistence to be much higher when controls are in place. Furthermore, we examine whether the control period affects the volatility of the premium. To identify the impact of controls on the premium, the AR model is specified as follows:

$$
\begin{aligned}
& x_{t}=\alpha_{0}+\alpha_{1} D_{\text {cont }}+\beta x_{t-1}+\beta_{\text {cont }} x_{t-1} D_{\text {cont }}+\sum_{j=1}^{k}\left(\phi_{j} \Delta x_{t-j}+\phi_{\text {cont }} \Delta x_{t-j} D_{\text {cont }}\right)+\varepsilon_{t}, \\
& \sigma_{t}^{2}=\alpha_{0}+\exp \left(\lambda D_{\text {cont }}\right)+\sum_{j=1}^{p} \alpha_{j} \varepsilon_{t-j}^{2}+\sum_{j=1}^{q} \lambda_{j} \sigma_{t-j}^{2} .
\end{aligned}
$$

$D_{\text {cont }}$ is a dummy equal to one during the control period and zero otherwise. For each stock, a different model is estimated, in which $k, p$, and $q$ are set in such way that the residuals do not contain any serial correlation or heteroskedasticity up to lag 10 . 
Table 5 shows the simple averages of the estimated thresholds and half-lives from the TAR model, and the half-lives and volatility changes from the AR model. ${ }^{33}$ As can be seen, the upper threshold goes up when controls on outflows are introduced (Argentina and South Africa), whereas the introduction of controls on inflows in Chile lowers the average floor of the band. ${ }^{34}$ Indonesia, by contrast, yields mixed results: the average shows only a slight widening of the band under the control period, which is driven by one of the two stocks in the portfolio.

In turn, AR estimates indicate that deviations from LOOP are, as expected, much more persistent in the periods when capital controls are in effect. The notable exception is, again, Indonesia, where half-lives are virtually identical, suggesting again that controls may have not been binding in this case. In addition, our results show that periods of controls on outflows were associated with an increase in the volatility of the premium, in line with the widening of the band. In Indonesia, by contrast, we see a slight decline in volatility in the control period compared to the tranquil period. This, once more, is consistent with the finding that controls did not impede arbitrage at the time.

\subsection{Integration in Crisis Periods}

If a crisis period indeed reflects a weakening of financial integration due to the increased risk, the bands of no arbitrage should widen during a crisis period. To test in a rigorous way whether this is indeed the case, we should estimate the TAR model for both tranquil and crisis periods on a stock-by-stock basis. However, the TAR model cannot be identified for the (typically short) crisis periods, and we have to rely primarily on the less informationally demanding AR model for the following discussion. As in the case of controls, the AR model is specified, as to allow for an increase in the volatility of the premium, as follows:

\footnotetext{
${ }^{33}$ For Korea, we cannot make a comparison between tranquil and control periods on a stock by stock basis as the restricted stocks have been restricted over the whole sample period, while the group of unrestricted stocks did not experience a period of controls. Furthermore, the TAR model cannot be estimated for the stocks in the portfolio of Venezuela due to the limited number of trading days in the control period.

${ }^{34}$ The results for individual stocks in each country are comparable. The estimations are available from the authors upon request.
} 


$$
\begin{aligned}
& x_{t}=c_{0}+c_{1} D_{c r i s}+\beta x_{t-1}+\beta_{c r i s} x_{t-1} D_{c r i s}+\sum_{j=1}^{k}\left(\phi_{j} \Delta x_{t-j}+\phi_{c r i s j} \Delta x_{t-j} D_{c r i s}\right)+\varepsilon_{t}, \\
& \sigma_{t}^{2}=\alpha_{0}+\exp \left(\lambda D_{\text {cris }}\right)+\sum_{j=1}^{p} \alpha_{j} \varepsilon_{t-j}^{2}+\sum_{j=1}^{q} \lambda_{j} \sigma_{t-j}^{2} .
\end{aligned}
$$

$D_{\text {cris }}$ is a dummy equal to one during the crisis period and zero otherwise; $k, p$, and $q$ are set in such way that the residuals do not contain any serial correlation or heteroskedasticity up to lag 10.

The upper panel in Table 6 compares the average linear half-lives estimated by the AR specification in tranquil and crisis periods. The results indicate that the estimated half-lives remain mostly unchanged during a crisis period. In fact, the individual stock estimates show that in 28 out of 30 cases there is no significant difference between the persistence of a shock in the tranquil and in the crisis period. ${ }^{35}$ On the other hand, the volatility of the premium does increase, as expected. Only in eight cases, we find that the volatility remains unchanged during the crisis.

The results on the linear model suggest that crisis episodes are associated with a higher volatility, but not with a higher persistence of deviations from LOOP - which would indicate weaker integration. After all, the fact that the AR half-lives remain unchanged suggests that the band of inaction does not widen. However, it is possible that two counteracting forces are at work: a widening of the band of inaction in combination with a decline of the persistence outside the band.

This possibility can only be examined using a TAR model. As noted, the short length of crises prevents a stock-by-stock estimation. To overcome this constraint, we pool the observations for the five most liquid stocks that traded during a crisis period (where liquidity is measured as before), and estimate the TAR model in both the crisis and the tranquil period - bearing in mind that by pooling we may be biasing the results. ${ }^{36}$ For robustness, we replicate the test using the fifteen most liquid stocks. The results, reported in the lower panel of Table 6, are consistent with the hypothesis that two countervailing forces (wider band-width, faster convergence) are at play, causing the AR

\footnotetext{
35 The results for the individual stocks are available upon request.

${ }^{36}$ Note that pooling across countries all stocks that traded during a crisis (30 stocks) would be even more problematic due to the large differences in volatility (which, for this sample, would range from 0.79 to 5.76). This may affect the TAR estimation.
} 
half-life to remain unchanged. However, a definitive test would have to wait for longer time series. In the meantime, whether crises, in addition to increasing volatility, reduce financial integration remains an open question.

\section{Conclusions}

This paper showed that the cross-market premium is a good gauge of the degree of financial integration as seen through the lens of LOOP, free from the comparability and aggregation problems that characterized previous attempts. It should be stressed, however, that this measure is not intended as a test of capital mobility. Transaction costs may inhibit financial integration even if capital is perfectly mobile.

Using the same methodology as in the PPP literature, our estimates revealed the presence of non-linearities in the behavior of the cross-market premium, in the form of no-arbitrage bands driven by transaction costs. More generally, our results showed that LOOP holds well in international equity markets: integration is stronger in financial markets than in goods markets, possibly due to a much lower incidence of transaction costs. As expected, integration is stronger for more liquid stocks, where these costs (including the associated liquidity risk) are likely to be smaller. Moreover, the crossmarket premium reflects accurately the effective impact of capital controls on international arbitrage, in the form of sizeable and persistent deviations from LOOP. Ultimately, the findings reported in this paper complement the literature on capital controls by providing a direct measure of de facto integration, through which the effectiveness of controls can be assessed more precisely. 


\section{References}

Alaganar, V. and R. Bhar, 2001, "Diversification Gains from ADRs and Foreign Equities: Evidence from Australian Stocks,” Journal of International Financial Markets, Institutions, and Money, vol. 11, pp. 97-113.

Auguste, S., K. Dominguez, H. Kamil, and L. Tesar, 2006, “Cross-Border Trading as a Mechanism for Capital Flight: ADRs and the Argentine Crisis," Journal of Monetary Economics, forthcoming.

Balke, N.S. and M.E. Wohar, 1998, "Nonlinear Dynamics and Covered Interest Rate Parity,” Empirical Economics, vol. 23, pp. 535-559.

Bekaert, G., and C. R. Harvey, 1995, “Time-Varying World Market Integration,” Journal of Finance, vol. 50, pp. 403-444.

Bekaert, G., C. R. Harvey, and A. Ng, 2005, "Market Integration and Contagion," Journal of Business, vol. 78, pp. 39-70, previous version appeared as NBER Working Paper No. 9510.

Broner, F. A., G. Lorenzoni, and S. L. Schmukler, 2004, "Why Do Emerging Markets Borrow Short Term?” World Bank Policy Research Working Paper No. 3389.

Canjels, C., G. Prakash-Canjels, and A. M. Taylor, 2004, "Measuring Market Integration: Foreign Exchange Arbitrage and the Gold Standard, 1879-1913,” The Review of Economics and Statistics, vol. 86, pp. 868-882.

Carrieri, F., V. Errunza, and K. Hogan, 2006, “Characterizing World Market Integration through Time,” Journal of Financial and Quantitative Analysis, forthcoming.

Cashin, P., M. S. Kumar, and C. J. McDermott, 1995, "International Integration of Equity Markets and Contagion Effects,” IMF Working Paper No. 95/110.

Chen, G. M., M. Firth, and O. M. Rui, 2002, "Stock Market Linkages: Evidence from Latin America,” Journal of Banking and Finance, vol. 26, pp. 1113-1141.

Chortareas, G. E. and R. L. Driver, 2001, "PPP and the Real Exchange Rate-Real Interest Rate Differential Puzzle Revisited: Evidence from Non-Stationary Panel Data,” Bank of England Working Paper No. 138.

Einzig, P., 1937, The Theory of Forward Exchange, London: Macmillan.

Flood, R. P. and A. K. Rose, 2005a, "Financial Integration: A New Methodology and an Illustration," Journal of the European Economic Association, vol. 3, pp. 13491359.

Flood, R. P. and A. K. Rose, 2005b, "Estimating the Expected Marginal Rate of Substitution: A Systematic Exploitation of Idiosyncratic Risk," Journal of Monetary Economics, vol. 52, pp. 951-969.

Frankel, J. and S. L. Schmukler, 1998, “Crisis, Contagion and Country Funds,” in: R. Glick (ed.) Managing Capital Flows and Exchange Rates, Cambridge University Press,

Frankel, J. and S. L. Schmukler, 2000, “Country Funds and Asymmetric Information,” International Journal of Finance and Economics, vol. 5, pp. 177-195.

Froot, K. A., and E. A. Dabora, 1999, "How are Stock Prices Affected by the Location of Trade,” Journal of Financial Economics, vol. 53, pp. 189-216.

Gagnon, L. and G. Karolyi, 2004, "Multi-Market Trading and Arbitrage,” mimeo, Queen's University and Ohio State University.

Hansen, B. E., 1997, "Inference in TAR models," Studies in Non-Linear Dynamics and Econometrics, vol. 2, pp. 1-14. 
Imbs, J., H. Mumtaz, M. O. Ravn, and H. Rey, 2005, "PPP Strikes Back: Aggregation and the Real Exchange Rate,” Quarterly Journal of Economics, vol. 120, pp. 143.

Imbs, J., H. Mumtaz, M. O. Ravn, and H. Rey, 2003, "Non-Linearities and Real Exchange Rate Dynamics," Journal of the European Economic Association, vol. 1, pp. 639-649.

Johansson, M. W., 2001, “TAR Models and Real Exchange Rates,” Working Paper Lund University Department of Economics No. 2001:21

Juhl, T., W. Miles, and M. Weidenmier, 2006, “Covered Interest Arbitrage: Then vs. Now," Economica, forthcoming.

Levine, R. and S. L. Schmukler, 2006, "Internationalization and Stock Market Liquidity," Review of Finance-Journal of the European Finance Association, vol. 10, pp. 153-187.

Levy Yeyati, E., S. L. Schmukler, and N. Van Horen, 2004, "The Price of Inconvertible Deposits: The Stock Market Boom during the Argentine Crisis," Economic Letters, vol. 83, pp. 7-13.

Levy Yeyati, E. and A. Uribe, 2000, "Crisis, Contagion and the Closed-End Country Fund Puzzle,” IMF Staff Papers, vol. 47, pp. 54-89.

MacDonald R. and J. Nagayasu, 2000, “The Long-Run Relationship between Real Exchange Rates and Real Interest Rate Differentials: A Panel Study," IMF Staff Papers, vol. 47, pp. 116-128.

Mancuso, A. J., B. K. Goodwin, and T. J. Grennes, 2003, "Nonlinear Aspects of Capital Market Integration and Real Interest Rate Equalization," International Review of Economics and Finance, vol. 3, pp. 283-303.

Masih, R. and A. M. M. Masih, 2001, "Long and Short Term Dynamic Causal Transmission amongst International Stock Markets," Journal of International Money and Finance, vol. 20, pp. 563-587.

Melvin, M., 2003, “A Stock Market Boom during a Financial Crisis? ADRs and Capital Outflows in Argentina,” Economics Letters, vol. 81, pp. 129-136.

Meese, R. A., and K. Rogoff, 1988, "Was It Real? The Exchange Rate-Interest Differential Relation over the Modern Floating-Rate Period,” Journal of Finance, vol. 43, pp. 933-948.

Michael, P., R. A. Nobay, and D. A. Peel, 1997, "Transaction Costs and Nonlinear Adjustment in Real Exchange Rates: an Empirical Investigation,” Journal of Political Economy, vol. 105, pp. 862-879.

Obstfeld, M. and A. M. Taylor, 1997, "Non-linear Aspects of Goods-Market Arbitrage and Adjustment: Heckscher's Commodity Points Revisited," Journal of the Japanese and International Economies, vol. 11, pp. 441-479.

Obstfeld, M. and A. M. Taylor, 2002, "Globalization and Capital Markets”, in M. D. Bordo, A. M. Taylor, and J. G. Williamson (eds.), Globalization and Capital Markets, University of Chicago Press.

Pasquariello, P., 2006, “Are Financial Crises Indeed 'Crises'? Evidence from the Emerging ADR Market,” mimeo, University of Michigan Business School.

Peel, D. A. and M. P. Taylor, 2002, "Covered Interest Rate Arbitrage in the Interwar Period and the Keynes-Einzig Conjecture," Journal of Money, Credit, and Banking, vol. 34, pp. 51-75. 
Prasad, E. S., K. Rogoff, S. J. Wei, and M. A. Kose, 2003, "Effects of Financial Globalization on Developing Countries: Some Empirical Evidence,” International Monetary Fund Occasional Paper No. 220.

Rabinovitch, R., A. C. Silva, and R. Susmel, 2003, "Returns on ADRs and Arbitrage in Emerging Markets,” Emerging Markets Review, vol. 4, pp. 225-247.

Scheicher, M., 2001, "The Comovements of Stock Markets in Hungary, Poland, and the Czech Republic,” International Journal of Finance and Economics, vol. 6, pp. 2739.

Sercu, P., R. Uppal, and C. Van Hulle, 1995, "The Exchange Rate in the Presence of Transaction Costs: Implications for Tests of Purchasing Power Parity,” Journal of Finance, vol. 50, pp. 1309-1319.

Soydemir, G., 2000, "International Transmission Mechanism of Stock Market Movements: Evidence from Emerging Equity Markets,” Journal of Forecasting, vol. 19, pp. 149-176.

Tong, H. and K. S. Lim, 1980, “Threshold Autoregression, Limit Cycles and Cyclical Data," Journal of the Royal Statistical Society, vol. 42, pp. 245-292.

Tong H., 1983, "Threshold Models and Non-linear Time Series Analysis,” Lecture Notes in Statistics Volume 21, Heidelberg: Springer-Verlag.

Tong, H., 1978, "On a Threshold Model," in C.H. Chen (ed.), Pattern Recognition and Signal Processing, Amsterdam: Sijthoff and Noordhoff. 


\section{Appendix I. Infrequently-Traded Stocks}

Trading frequencies of both the underlying stock and the DR have an important effect on the behavior of the premium, which becomes clear when comparing the average mean and standard deviation of the stocks included in our sample with those of the stocks excluded. Specifically, the average mean (standard deviation of the) premium for the included stocks equals 0.16 (2.12), while it equals 5.39 (9.39) for the excluded stocks, suggesting that the average price deviation is substantially larger and more volatile for the last group.

This insight is confirmed by a more careful exploration. Regarding liquidity, we can broadly distinguish three cases: (1) both the underlying stock and the DR are traded frequently, (2) the underlying stock and/or the DR are traded infrequently, and (3) the underlying stock (DR) is not traded while the DR (underlying stock) is traded.

Figure A1 displays the difference in the pattern of the cross-market premium in these three cases. In the first case, the premium oscillates around zero with a small standard deviation. In the second case, the premium also oscillates around zero but with a wider standard deviation. Due to the infrequency of trading in either stock or both stocks, there are periods with no arbitrage pressure, when the premium can diverge from zero for a long time. In the last case, the premium can be negative or positive over an extended period and there is no pressure towards zero. As expected, the last case hardly occurs in practice.

As we are interested in arbitrage issues, we restrict our sample and only include the stocks that fit the first category. Including all stocks in the sample, i.e. disregarding their obvious differences, would have an important impact on our results as can be seen in Figure A2. The figure reports the regression results and the partial regression plots of regressing the absolute mean of the premium on trading frequency of the stock and country dummies, plus regressing the standard deviation of the premium on the same explanatory variables. The trading frequency equals the number of days both the underlying stock and the DR were traded during the sample period, as a percentage of the total number of potential trading days. The graphs in Figure A2 reveal the presence of a significant negative correlation between the trading frequency and the absolute mean and the standard deviation of the premium. 
Even when stocks fit the first category, non-trading days exist. On those days, the cross-market premium reflects spurious price divergences. The fact that a premium on non-trading days may not represent a price divergence, but rather the evolution of the price over time, should be reflected in a larger premium on non-trading days, as compared to the premium on days both the underlying stock and the DR are traded. Indeed, for all stocks included in our sample the mean of the absolute value of the premium on non-trading days exceeds the one on trading days. On average, the premium on trading days is half that on non-trading days. This justifies the choice for our empirical analysis to use only the premium on days when both the underlying stock and the DR are traded. $^{37}$

\footnotetext{
${ }^{37}$ One could argue that also the stocks in the second category are subject to periods in which arbitrage takes place and are therefore interesting to include in the sample. However, as we are only interested in the premium on trading days due to its spurious nature on non-trading days, the number of observations during the sample period for these stocks is too small to be able to estimate a TAR model. As a result, a different methodology would be warranted for these stocks, which goes beyond the scope of this paper.
} 


\section{Table 1 - Summary Statistics for Tranquil Periods}

The table shows the summary statistics of the cross-market premium during tranquil periods. The cross-market premium is defined as the percentage difference between the dollar price of the stock in the domestic market and the price of the corresponding DR in New York. The country summary statistics are based on the simple average of the premium of the stocks in each country's portfolio. The pooled data contain these country averages. All statistics are based on the days on which both the underlying stock and the DR were traded.

\begin{tabular}{lcccccc}
\hline Country & Mean & Median & Std. Dev. & 5th Pctile & 95th Pctile & Obs. \\
\hline Argentina & 0.06 & 0.00 & 0.72 & -0.97 & 1.35 & 2,138 \\
Brazil & 0.04 & 0.01 & 1.21 & -1.90 & 1.94 & 2,301 \\
Chile & 0.09 & 0.07 & 0.62 & -0.85 & 1.13 & 1,587 \\
Indonesia & 0.58 & 0.53 & 1.89 & -2.32 & 3.88 & 1,315 \\
Korea & 1.59 & 1.17 & 3.80 & -3.76 & 7.87 & 972 \\
Mexico & 0.01 & -0.02 & 0.89 & -1.36 & 1.47 & 2,379 \\
Russia & 0.11 & 0.23 & 1.52 & -2.50 & 2.30 & 1,371 \\
South Africa & -0.31 & -0.25 & 1.22 & -2.46 & 1.51 & 2,031 \\
Venezuela & 0.09 & -0.05 & 2.26 & -3.40 & 4.21 & 1,439 \\
Pooled & 0.15 & 0.04 & 1.65 & -2.10 & 2.73 & 15,533 \\
\hline
\end{tabular}




\section{Table 2 - Results Most Liquid Stocks in Tranquil Periods}

This table reports TAR and AR estimates for each country's most liquid stock (classified according to value traded, see main text) for tranquil periods. "Thres" stands for the threshold estimated by the TAR model and LLR is the accompanying log likelihood ratio of the TAR significance test. Thresholds are expressed in percentage terms, and reflect both the lower as well as the upper band. Half-life of the TAR model reflects the half-life of a shock when outside the band of no-arbitrage. Half-lives are equal to $\ln (0.5) / \mathrm{ln}(1$-beta). Observations are based on the TAR model (in general the observations of the AR model are the same, except in some cases where more lags were needed to correct for serial correlation). Both TAR and AR models are corrected for heteroskedasticity and serial correlation. For comparison, the halflives estimated by Obstfeld and Taylor (1997) are converted into days instead of months, assuming that one month contains on average 20 trading days.

\begin{tabular}{|c|c|c|c|c|c|c|}
\hline Country & Stock & Obs. & $\begin{array}{l}\text { TAR } \\
\text { Thres } \\
\end{array}$ & $\begin{array}{l}\text { TAR } \\
\text { LLR } \\
\end{array}$ & $\begin{array}{c}\text { TAR } \\
\text { Half-life }\end{array}$ & $\begin{array}{c}\text { AR } \\
\text { Half-life }\end{array}$ \\
\hline Argentina & ypf & 1,545 & 0.09 & 13.24 & 0.01 & 0.39 \\
\hline Brazil & the & 1,139 & 0.17 & 5.64 & 0.48 & 0.62 \\
\hline Chile & ctc & 1,361 & 0.13 & 7.90 & 0.57 & 0.75 \\
\hline Indonesia & tlk & 1,118 & 0.09 & 3.69 & 0.88 & 1.06 \\
\hline Korea & $\mathrm{kb}$ & 496 & 0.10 & 5.10 & 0.35 & 0.45 \\
\hline Mexico & amx & 556 & 0.18 & 12.29 & 0.95 & 1.66 \\
\hline Russia & ros & 1,210 & 0.15 & 2.71 & 0.61 & 0.90 \\
\hline South Africa & $\mathrm{au}$ & 1,631 & 0.05 & 3.20 & 0.68 & 0.72 \\
\hline Venezuela & vnt & 966 & 0.12 & 3.43 & 0.90 & 0.99 \\
\hline Pooled & & 7,872 & 0.02 & 3.53 & 0.99 & 1.02 \\
\hline \multicolumn{7}{|c|}{ Obstfeld and Taylor (1997) Results } \\
\hline Mexico & & 180 & 4.00 & 34.20 & 382 & 428 \\
\hline South Africa & & 180 & 23.00 & 76.90 & 68 & 506 \\
\hline Pooled & & 5,387 & 3.00 & 77.40 & 182 & 232 \\
\hline
\end{tabular}




\section{Table 3 - Crisis Periods}

This table reports the crisis periods. A crisis period is identified when the volatility in the exchange market pressure (EMP), defined as the weighted average of the daily changes in the interest rate and the log difference of the exchange rate, exceeds the threshold. The threshold is defined as the mean of the EMP volatility plus one standard deviation. A crisis ends if the EMP volatility falls below the threshold and remains there for three months (the end date is set equal to the date of the initial decline).

\begin{tabular}{|c|c|c|c|}
\hline Country & Period & Start date & End date \\
\hline Argentina & Crisis 1 & 11/01/2001 & 06/11/2002 \\
\hline \multirow[t]{2}{*}{ Brazil } & Crisis 1 & 03/07/1995 & 04/17/1995 \\
\hline & Crisis 2 & 01/13/1999 & 02/24/1999 \\
\hline Chile & Crisis 1 & 01/08/1998 & 02/24/1998 \\
\hline Indonesia & Crisis 1 & 08/15/1997 & 11/12/1998 \\
\hline \multirow[t]{2}{*}{ Korea } & Crisis 1 & $12 / 20 / 1994$ & 03/21/1995 \\
\hline & Crisis 2 & 11/20/1997 & 03/16/1998 \\
\hline Mexico & Crisis 1 & $12 / 20 / 1994$ & 06/02/1995 \\
\hline Russia & Crisis 1 & 05/25/1998 & 11/11/1998 \\
\hline \multirow[t]{2}{*}{ South Africa } & Crisis 1 & 04/29/1996 & 08/30/1996 \\
\hline & Crisis 2 & 05/25/1998 & 11/20/1998 \\
\hline \multirow[t]{2}{*}{ Venezuela } & Crisis 1 & 02/13/2002 & 07/24/2002 \\
\hline & Crisis 2 & 01/08/2003 & 02/27/2003 \\
\hline
\end{tabular}


Table 4 - Summary Statistics for Tranquil, Crisis, and Control Periods

The table shows the summary statistics of the cross-market premium over the different periods. The cross-market premium is defined as the percentage difference between the dollar price of the stock in the domestic market and the price of the corresponding DR in New York. The country summary statistics are based on the simple average of the cross-market premium of the stocks in each country's portfolio. The pooled data contain these country averages. Summary statistics for crisis periods exclude crisis periods that coincide with control periods. In the case of Korea, the summary statistics for the tranquil period are derived from the average cross-market premium of the unrestricted stocks and the ones for the different control periods are derived from the average cross-market premium of the restricted stocks, as explained in the main text. For Korea, three control periods are distinguished. The first period of high restrictions lasts until January 1999, the second period of medium restrictions goes from January 1999 to November 2000, and the third period of low restrictions covers November 2001 onwards (see main text and Appendix Table 3). ***, **, and

* indicate whether the mean is statisically different from the mean in the tranquil period at one, five, or ten percent significance level, respectively.

Pooled data

\begin{tabular}{lcccccc}
\hline Period & Mean & Median & Std. Dev. & 5th Pctile & 95th Pctile & Obs. \\
\hline Tranquil & 0.15 & 0.04 & 1.65 & -2.10 & 2.73 & 15,533 \\
Crisis & $-1.06 * * *$ & -0.92 & 3.48 & -6.31 & 3.92 & 918 \\
Control inflows & $-10.10 * * *$ & -3.40 & 13.93 & -38.11 & 1.10 & 3,733 \\
Control outflows & $31.51 * * *$ & 30.40 & 21.59 & 1.32 & 65.93 & 1,996 \\
\hline
\end{tabular}

By Country

\begin{tabular}{|c|c|c|c|c|c|c|c|}
\hline Country & Period & Mean & Median & Std. Dev. & 5th Pctile & 95th Pctile & Obs. \\
\hline \multirow[t]{2}{*}{ Argentina } & Tranquil & 0.06 & 0.00 & 0.72 & -0.97 & 1.35 & 2,138 \\
\hline & Control outflows & $6.35 * * *$ & 4.70 & 7.54 & -0.85 & 19.90 & 344 \\
\hline \multirow[t]{2}{*}{ Brazil } & Tranquil & 0.04 & 0.01 & 1.21 & -1.90 & 1.94 & 2,301 \\
\hline & Crisis & $1.07 * * *$ & 0.01 & 3.73 & -3.80 & 8.79 & 53 \\
\hline \multirow[t]{2}{*}{ Chile } & Tranquil & 0.09 & 0.07 & 0.62 & -0.85 & 1.13 & 1,587 \\
\hline & Control inflows & $-2.20 * * *$ & -2.24 & 0.88 & -3.45 & -0.69 & 750 \\
\hline \multirow[t]{3}{*}{ Indonesia } & Tranquil & 0.58 & 0.53 & 1.89 & -2.32 & 3.88 & 1,315 \\
\hline & Crisis & $-1.27 * * *$ & -1.27 & 2.84 & -6.32 & 3.28 & 300 \\
\hline & Control inflows & 0.48 & 0.50 & 1.19 & -1.48 & 2.30 & 689 \\
\hline \multirow[t]{4}{*}{ Korea } & Tranquil & 1.59 & 1.17 & 3.80 & -3.76 & 7.87 & 972 \\
\hline & Control inflows - high & $-31.18 * * *$ & -31.75 & 8.89 & -46.10 & -16.96 & 1,011 \\
\hline & Control inflows - medium & $-8.84 * * *$ & -6.25 & 8.11 & -31.69 & -1.46 & 670 \\
\hline & Control inflows - low & $-3.60 * * *$ & -3.13 & 1.58 & -7.75 & -1.71 & 612 \\
\hline \multirow[t]{2}{*}{ Mexico } & Tranquil & 0.01 & -0.02 & 0.89 & -1.36 & 1.47 & 2,379 \\
\hline & Crisis & $-1.12 * * *$ & -0.94 & 1.80 & -4.88 & 1.26 & 109 \\
\hline \multirow[t]{2}{*}{ Russia } & Tranquil & 0.11 & 0.23 & 1.52 & -2.50 & 2.30 & 1,371 \\
\hline & Crisis & $-3.22 * * *$ & -2.69 & 5.44 & -13.85 & 5.14 & 108 \\
\hline \multirow[t]{3}{*}{ South Africa } & Tranquil & -0.31 & -0.25 & 1.22 & -2.46 & 1.51 & 2,031 \\
\hline & Crisis & -0.46 & -0.15 & 1.85 & -3.77 & 1.95 & 206 \\
\hline & Control outflows & $33.13 * * *$ & 32.97 & 14.23 & 11.59 & 55.73 & 1,277 \\
\hline \multirow[t]{3}{*}{ Venezuela } & Tranquil & 0.09 & -0.05 & 2.26 & -3.40 & 4.21 & 1,439 \\
\hline & Crisis & $-0.68 * * *$ & -1.75 & 4.83 & -6.24 & 9.51 & 122 \\
\hline & Control outflows & $49.06 * * *$ & 57.24 & 29.05 & -0.41 & 89.12 & 375 \\
\hline
\end{tabular}




\section{Table 5 - Financial Market Integration in Periods of Capital Controls}

The table shows TAR and AR estimates in periods of capital controls. The TAR estimates reflect the simple averages of the estimated thresholds and half-lives for the stocks in each country's portfolio that are traded during the time controls were in effect. The AR estimates reflect the simple averages of the estimated half-lives and volatility for the same stocks. "Thres-up" refers to the upper threshold estimated by the TAR model and "Thres-low" refers to the lower threshold. In the tranquil period, both thresholds are assumed to be the same. In the control period, the threshold that should not be affected by the controls (the floor in the case of controls on outflows and the ceiling in the case of controls on inflows) is set equal to the value estimated in the tranquil period. Thresholds are expressed in percentage terms. Half-life of TAR model implies the half-life of a shock when outside the band of no-arbitrage. Half-lives are equal to $\ln (0.5) / \ln (1-$ beta). "Volatility" in the AR model reflects the impact of the control period on the conditional variance. Both TAR and AR models are corrected for heteroskedasticity and serial correlation.

\begin{tabular}{|c|c|c|c|c|c|c|}
\hline Country & Period & $\begin{array}{c}\text { TAR } \\
\text { Average } \\
\text { Thres-up }\end{array}$ & $\begin{array}{c}\text { TAR } \\
\text { Average } \\
\text { Thres-low }\end{array}$ & $\begin{array}{c}\text { TAR } \\
\text { Average } \\
\text { Half-life }\end{array}$ & $\begin{array}{c}\text { AR } \\
\text { Average } \\
\text { Half-life }\end{array}$ & $\begin{array}{c}\text { AR } \\
\text { Avg. Volatility } \\
\text { Increase }\end{array}$ \\
\hline \multirow[t]{2}{*}{ Argentina } & Tranquil & 0.29 & 0.29 & 0.69 & 0.96 & \\
\hline & Control Outflows & 7.8 & 0.29 & 3.65 & 4.41 & 2.74 \\
\hline \multirow[t]{2}{*}{ Chile } & Tranquil & 0.23 & 0.23 & 0.56 & 0.84 & \\
\hline & Control Inflows & 0.23 & 3.11 & 1.08 & 3.42 & -0.26 \\
\hline \multirow[t]{2}{*}{ Indonesia } & Tranquil & 0.17 & 0.17 & 1.42 & 1.31 & \\
\hline & Control Inflows & 0.17 & 1.19 & 1.04 & 1.31 & -1.25 \\
\hline \multirow[t]{2}{*}{ South Africa } & Tranquil & 0.09 & 0.09 & 0.71 & 0.92 & \\
\hline & Control Outflows & 53.36 & 0.09 & 4.28 & 44.46 & 1.55 \\
\hline \multirow[t]{2}{*}{ Venezuela } & Tranquil & - & - & - & 1.17 & \\
\hline & Control Outflows & - & - & - & 53.92 & 1.53 \\
\hline
\end{tabular}




\section{Table 6 - Financial Market Integration during Crisis Periods}

The table shows how AR and TAR estimates vary during crisis periods. The upper panel shows, for the stocks that are traded during a crisis period, the average half-lives in the tranquil and crisis periods and the average increase in volatility. "Volatility" reflects the impact of the crisis period on the conditional variance. In the lower panel the TAR estimations are provided for the group of the five most liquid stocks (tne, tv, au, gfi, and hmy) and the group of the fifteen most liquid stocks (tne, tv, au, gfi, hmy, emt, ssl, tlk, vnt, sid, ara, dro, kof, elp, and saj). Liquidity is based value traded, see main text. Half-life of TAR model implies the half-life of a shock when outside the band of no-arbitrage. Half-lives are equal to $\ln (0.5) / \ln (1$-beta). Both TAR and AR models are corrected for heteroskedasticity and serial correlation. Thresholds are expressed in percentage terms. ***,**,* refer to significance at the one, five and ten percent level respectively.

\begin{tabular}{llcc}
\hline & \multicolumn{3}{l}{ Results AR Estimations - Average } \\
\hline Country & Period & $\begin{array}{c}\text { Average } \\
\text { Half-life }\end{array}$ & $\begin{array}{c}\text { Avg. Volatility } \\
\text { Increase }\end{array}$ \\
\hline Brazil & Tranquil & 0.71 & \\
& Crisis & 0.71 & 5.19 \\
Indonesia & Tranquil & 1.59 & \\
& Crisis & 1.59 & 2.13 \\
Mexico & Tranquil & 0.80 & \\
& Crisis & 0.75 & 2.06 \\
Russia & Tranquil & 0.71 & \\
\multirow{5}{*}{ South Africa } & Crisis & 1.92 & 3.62 \\
& Tranquil & 1.08 & \\
Venezuela & Crisis & 1.08 & 0.84 \\
& Tranquil & 1.23 & \\
& Crisis & 1.23 & 1.75 \\
\hline
\end{tabular}

Results TAR Estimations - Pooled Data

\begin{tabular}{llccc}
\hline & Period & TAR & TAR & TAR \\
& & Thres & LLR & Half-life \\
\hline Top 5 & Tranquil & 0.02 & 0.28 & $0.88^{* * *}$ \\
& Crisis & 0.36 & 5.70 & $0.36^{* * *}$ \\
\multirow{2}{*}{ Top 15 } & Tranquil & 0.02 & 0.42 & $1.25^{* * *}$ \\
& Crisis & 0.22 & 3.41 & $0.71^{* * *}$ \\
\hline
\end{tabular}




\section{Figure 1 - Non-linearities in the Evolution of the Premium}

The upper scatter displays the correlation between the estimated half-lives of the AR model and the estimated thresholds. The lower scatter displays the correlation between the estimated half-lives of the AR model and the reduction in half-lives when non-linearities are taken into acocunt. Halflives are equal to $\ln (0.5) / \ln (1$-beta). Correlation coefficients with p-values in brackets are shown in the graphs.
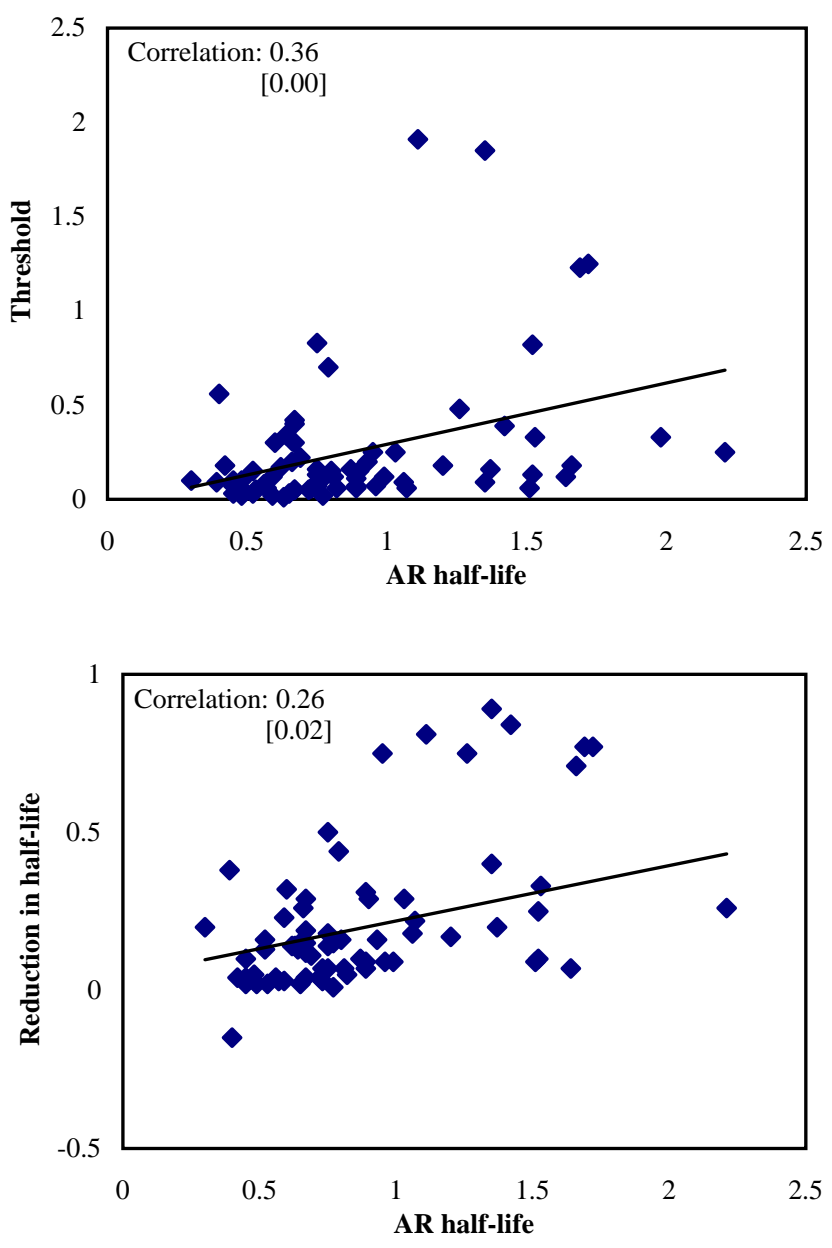


\section{Figure 2 - Liquid versus Illiquid Stocks}

The upper scatter shows the partial regression plot from regressing the estimated threshold on stock liquidity (based on the log of the average of the mean value traded of the underlying stock and the DR) and country dummies. The middle scatter displays the partial regression plot from regressing the estimated half-lives of a shock when outside the band of no-arbitrage on liquidity and country dummies. The lower scatter displays the partial regression plot from regressing the half-life estimated by an AR model on liquidity and country dummies. Half-lives are equal to $\ln (0.5) / \ln (1-$ beta $)$. The trendlines represent the regression estimates, t-values are presented in parentheses.

\section{TAR-model}

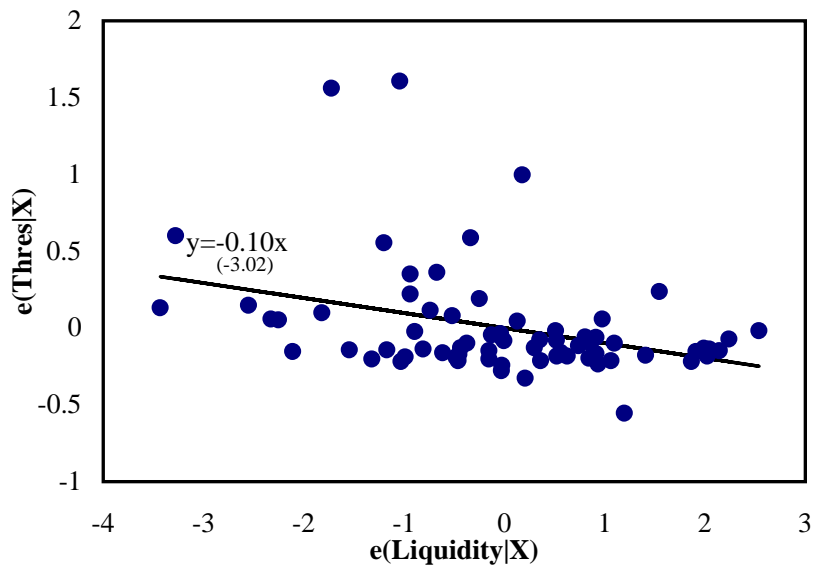

TAR-model

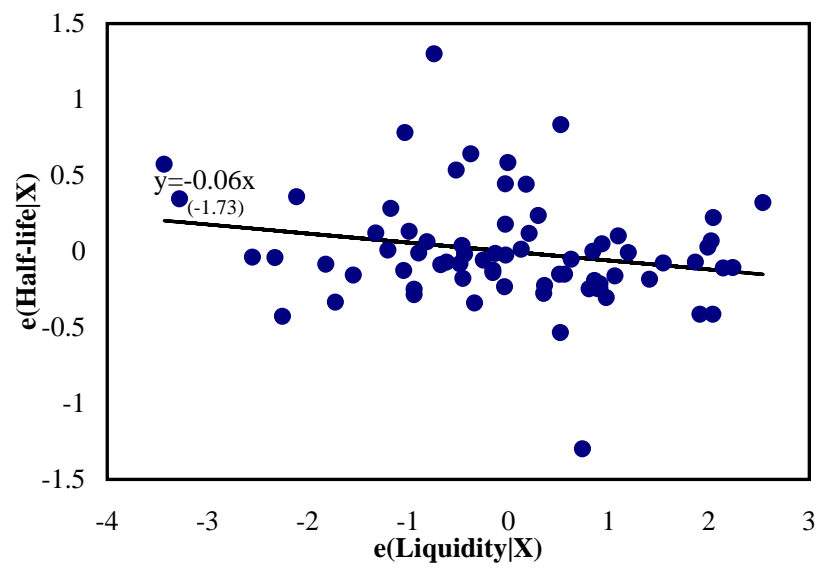

AR-model

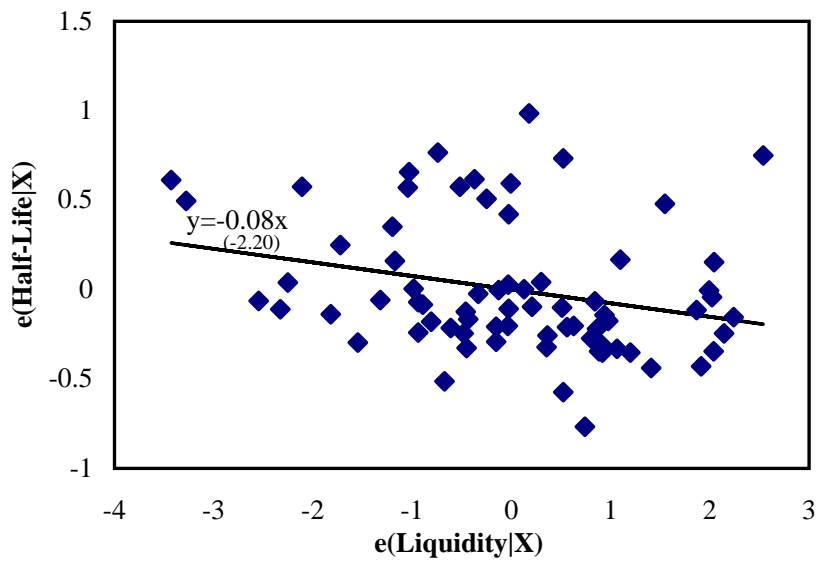




\section{Figure 3 - Cross-Market Premium per Country}

The graphs show the simple average of the cross-market premium of all stocks in the portfolio of each country. The cross-market premium is defined as the percentage difference between the dollar price of the stock in the domestic market and the price of the corresponding DR in New York. A positive premium implies that the price of the underlying stock is higher than the DR price. As explained in the main text, for Korea we include a graph showing the average cross-market premium of the restricted stocks and one of the unrestricted stocks. For the restricted stocks three control periods are distinguished. The first period (high restrictions) lasts until January 1999, the second period (medium restrictions) goes from January 1999 until November 2000, and the third period (low restrictions) covers November 2000 onwards. The light shaded areas indicate crisis periods and the darker shaded areas indicate control periods.
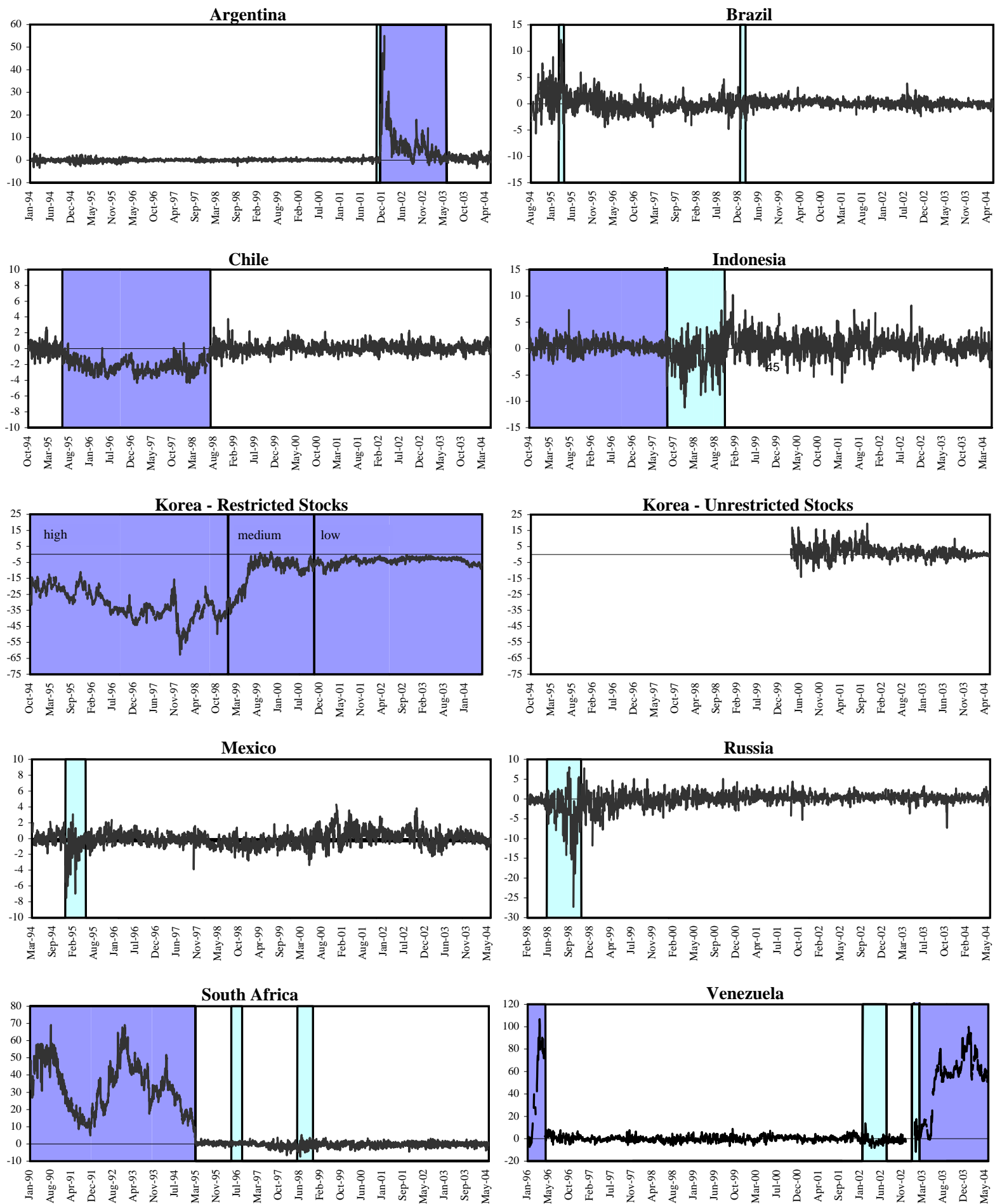


\section{Figure A1 - Differences in Cross-Market Premium}

The graphs show the cross-market premium of three different stocks. The upper panel shows the premium of a stock that is characterized by frequent trading in both the underlying stock as well as the DR. The middle panel indicates the behavior of the premium when the underlying stock and/or the DR only trades infrequently. The lower panel shows the premium of a stock for which either the underlying stock or the DR does not trade. The cross-market premium is defined as the percentage difference between the dollar price of the stock in the domestic market and the price of the corresponding DR in New York. A positive premium implies that the price of the underlying stock is higher than the DR price.

\section{Category 1: Fomento Economico Mexicano (Mexico)}

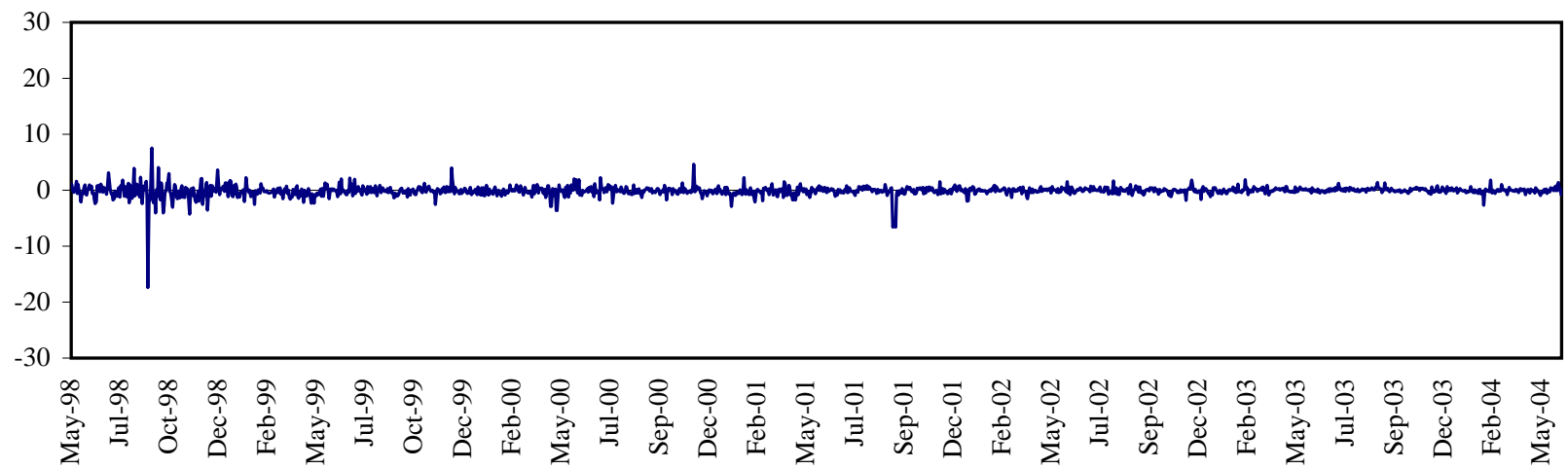

Category 2: Ambev (Brazil)

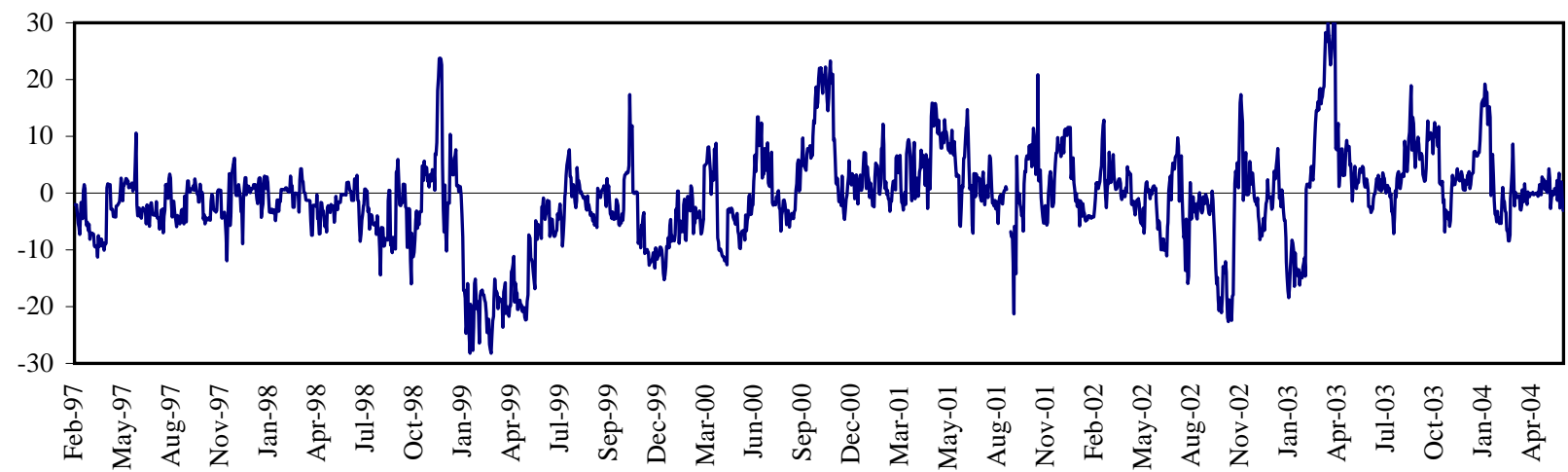

Category 3: Nortel (Argentina)

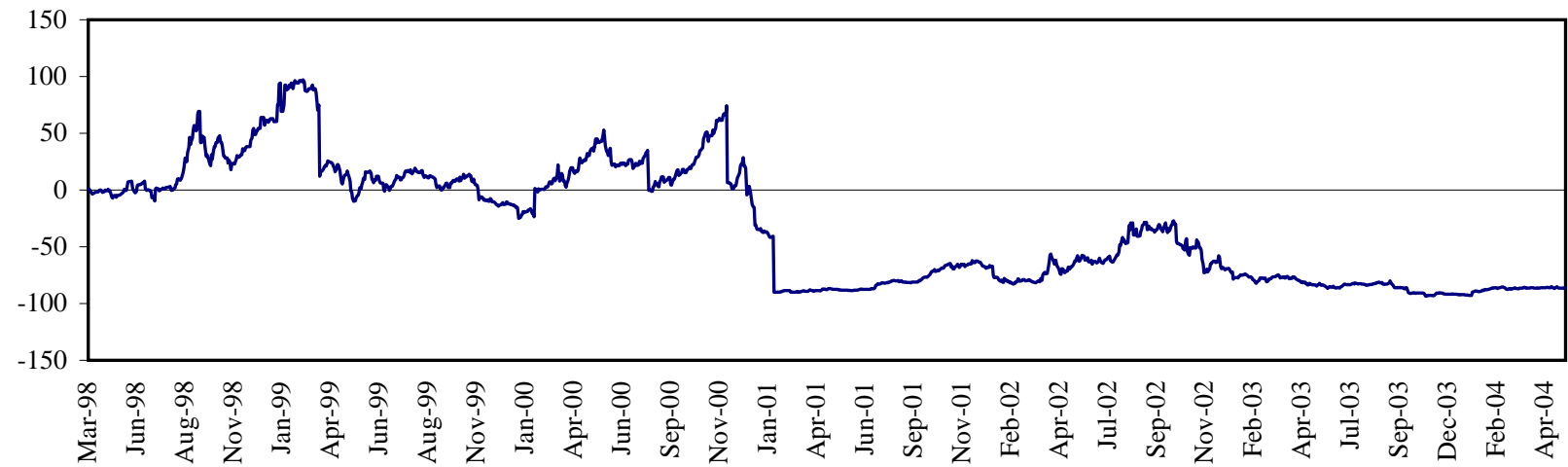




\section{Figure A2 - Impact of Trading Frequency on the Premium}

The upper scatter shows the partial regression plot from regressing the absolute value of the premium on trading frequency (equal to the ratio of the number of days both the underlying stock and the DR are traded to the total number of possible trading days in the sample period) and country dummies. The lower scatter displays the partial regression plot from regressing the standard deviation of the premium on trading frequency and country dummies. Both the absolute mean and the standard deviation are calculated including both trading as well as non-trading days. In both regressions three outliers are excluded, including them does not change the results. The trendlines represent the regression estimates, t-values are presented in parentheses.
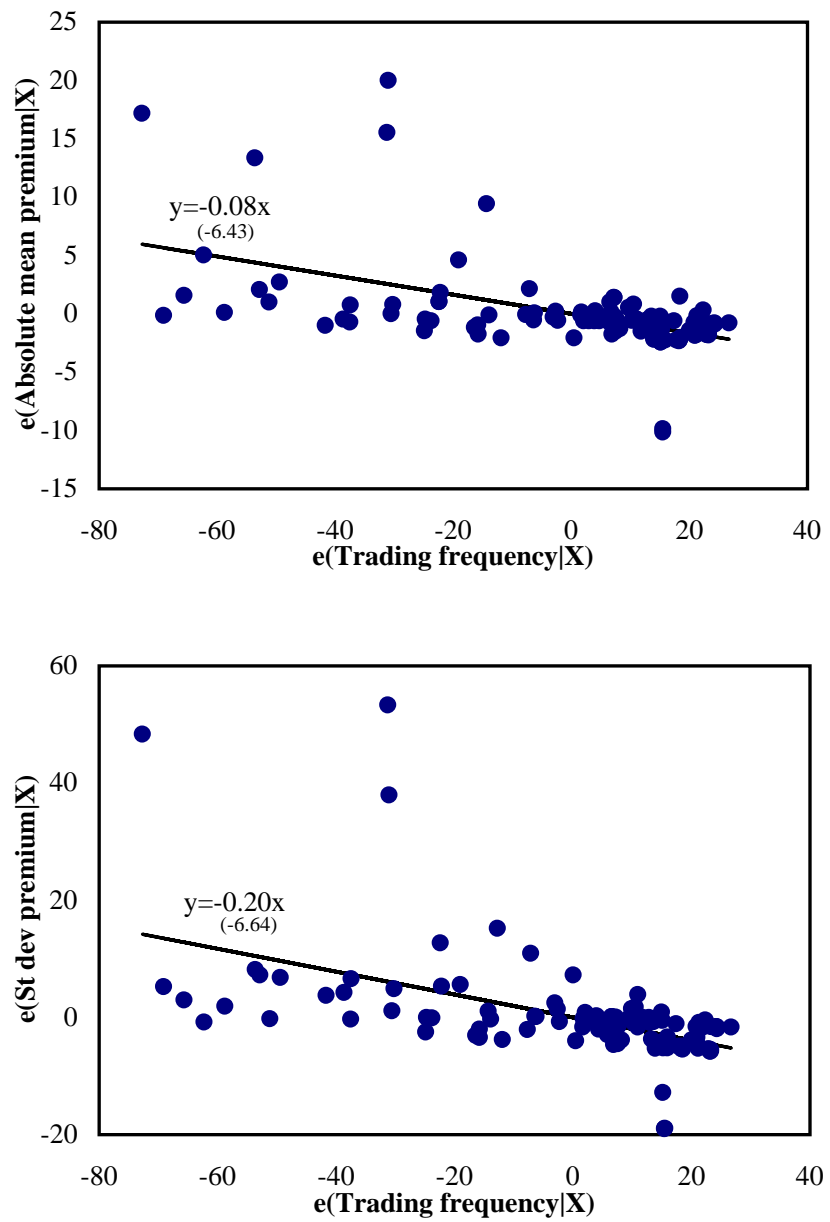


\section{Appendix Table 1 - Firms in Sample}

\begin{tabular}{|c|c|c|c|c|c|c|c|c|}
\hline Firm Name & Abbreviation & Sample Period & Firm Name & Abbreviation & Sample Period & Firm Name & Abbreviation & Sample Period \\
\hline Argentina & & & Brazil & & & Mexico & & \\
\hline YPF & ypf & 1/12/1994-12/31/2000 & TIM & tsu & 11/16/1998-5/31/2004 & America Movil - series A & amo & $2 / 7 / 2002-5 / 31 / 2004$ \\
\hline Petrobas Energia & pze & $1 / 26 / 2000-5 / 31 / 2004$ & Tele Nordeste Celular & tnd & $11 / 16 / 1998-5 / 31 / 2004$ & America Movil - series I & $\mathrm{amx}$ & $2 / 7 / 2002-5 / 31 / 2004$ \\
\hline Telecom Argentinč & teo & $12 / 9 / 1994-5 / 31 / 2004$ & Tele Leste Celular & the & 11/16/1998-5/31/2004 & Cemex & $\mathrm{cx}$ & $5 / 8 / 2002-5 / 31 / 2004$ \\
\hline Telefonica de Argentinč & tar & 3/8/1994-12/31/2000 & Tele Norte Celular & ten & 11/16/1998-5/31/2004 & Grupo Televisa & $\mathrm{tv}$ & 3/23/1994-5/31/2004 \\
\hline Transportadora de Gas del Sur & $\operatorname{tgs}$ & $1 / 4 / 1995-5 / 31 / 2004$ & & & & Fomento Economico Mexicanc & fmx & 5/11/1998-5/31/2004 \\
\hline BBVA Banco Frances & bfr & $1 / 12 / 1994-5 / 31 / 2004$ & Chile & & & Coca-cola Femsa & kof & $4 / 6 / 1994-12 / 31 / 1998$ \\
\hline MetroGAS & mgs & 1/25/1995-12/31/1998 & Banco Santander Chile & san & 5/22/1997-5/31/2004 & Grupo Elektra & ekt & 12/5/1994-5/31/2004 \\
\hline \multirow{2}{*}{ IRSA Inversiones y Representacione: } & irs & $1 / 20 / 1994-5 / 31 / 2004$ & Enersis & eni & 10/17/1994-5/31/2004 & Grupo Imsa & imy & 12/11/1996-12/31/1999 \\
\hline & & & Endesa - Chile & eoc & 10/17/1994-5/31/2004 & Grupo Industrial Maseca (Gimsa) & msk & 5/17/1994-12/31/1999 \\
\hline Brazil & & & Telefonica CTC Chile & ctc & 10/17/1994-5/31/2004 & Controladora Comercial Mexicanc & sim & $12 / 8 / 1994-12 / 31 / 1997$ \\
\hline Petroleo Brasileiro & pbr & 8/10/2000-5/31/2004 & Embotelladora Andina & akoa & 4/7/1997-5/31/2004 & Grupo Simec & $\mathrm{mcm}$ & 10/11/1996-12/31/2001 \\
\hline Petroleo Brasileiro - preferrec & pbra & $2 / 22 / 2001-5 / 31 / 2004$ & Distribucion y Servicio D\&S & dys & $10 / 8 / 1997-5 / 31 / 2004$ & Grupo Casa Saba & sab & 4/6/1994-12/31/1997 \\
\hline Companhia Vale do Rio Doce & rio & $3 / 21 / 2002-5 / 31 / 2004$ & Compania Cervecerias Unidas & си & 10/17/1994-5/31/2004 & Savia & saj & 4/6/1994-12/31/2000 \\
\hline Banco Itau Holding Financeira & itu & 2/19/2002-5/31/2004 & Lan Airlines & lfl & 1/1/1999-12/31/2001 & & & \\
\hline Telesp & tsp & 6/1/2001-5/31/2004 & Sociedad Quimica y Minera & sqm & 10/17/1994-5/31/2004 & Russia & & \\
\hline Embraer & erj & 7/20/2000-5/31/2004 & Quinenco & lq & 6/25/1997-5/31/2004 & Tatneft & $\mathrm{tnt}$ & 3/30/1998-12/31/2002 \\
\hline Tele Norte Leste (Telemar', & the & $11 / 16 / 1998-5 / 31 / 2004$ & Masisa & mys & 10/17/1994-5/31/2004 & Rostelecom & ros & 2/17/1998-5/31/2004 \\
\hline Companhia Siderurgica Naciona & sid & $1 / 1 / 1999-5 / 31 / 2004$ & Gener & $\mathrm{gnr}$ & 10/17/1994-12/31/2000 & & & \\
\hline Aracruz Celulose & ara & 8/2/1994-5/31/2004 & & & & South Africa & & \\
\hline Gerdau & ggb & 3/10/1999-5/31/2004 & Indonesia & & & Sasol & ssl & 1/1/1996-5/31/2004 \\
\hline Votorantim Celulose e Papel & vср & $4 / 13 / 2000-5 / 31 / 2004$ & Telekomunikasi Indonesic & tlk & $11 / 14 / 1995-5 / 31 / 2004$ & Anglogold Ashanti & 然 & $1 / 1 / 1990-5 / 31 / 2004$ \\
\hline CEMIG & cig & 9/18/2001-5/31/2004 & Indosat & iit & $10 / 19 / 1994-5 / 31 / 2004$ & Gold Fields & gfi & $8 / 1 / 1990-5 / 31 / 2004$ \\
\hline Unibanco - Uniao de Bancos & ubb & $1 / 1 / 2000-5 / 31 / 2004$ & & & & Harmony Gold Mining & hmy & $1 / 1 / 1997-5 / 31 / 2004$ \\
\hline Acucar & cbd & $5 / 29 / 1997-5 / 31 / 2004$ & Korea & & & Sappi & spp & 1/1/2000-5/31/2004 \\
\hline Braskem & bak & $1 / 1 / 2000-5 / 31 / 2004$ & SK Telecom & skt & 6/27/1996-5/31/2004 & Drdgold & dro & $1 / 1 / 1998-5 / 31 / 2004$ \\
\hline Tele Centro Oeste Celular & tro & $11 / 16 / 1998-5 / 31 / 2004$ & Керсо & kep & $10 / 27 / 1994-5 / 31 / 2004$ & Randgold and Exploration Company & ran & $3 / 12 / 1997-12 / 31 / 2000$ \\
\hline Embratel & emt & $11 / 16 / 1998-5 / 31 / 2004$ & Posco & pos & 10/14/1994-5/31/2004 & & & \\
\hline Copel & elp & $7 / 30 / 1997-5 / 31 / 2004$ & KT Corporation & ktc & 5/25/1999-5/31/2004 & Venezuela & & \\
\hline Telemig Celular & $\mathrm{tmb}$ & $11 / 16 / 1998-5 / 31 / 2004$ & Kookmin Bank & $\mathrm{kb}$ & $11 / 9 / 2001-5 / 31 / 2004$ & Cantv & vnt & 1/3/1997-5/31/2004 \\
\hline Ultrapar & ugp & $10 / 13 / 1999-5 / 31 / 2004$ & Hanaro Telecom & han & $3 / 29 / 2000-12 / 31 / 2003$ & Mavesa & mav & 1/1/1996-3/28/2001 \\
\hline
\end{tabular}




\section{Appendix Table 2 - TAR and AR Estimations for All Stocks}

TAR and AR estimations for all stocks in each country's portfolio for the tranquil period. "Thres" refers to the threshold estimated by the TAR model and LLR is the accompanying log likelihood ratio of the TAR significance test. Thresholds are expressed in percentage terms, and reflect both the lower as well as the upper band. Half-life of the TAR model reflects the half-life of a shock when outside the band of no-arbitrage. Half-lives are equal to $\ln (0.5) / \ln (1$-beta). "Percent in" indicates the percentage of the observations that falls in the no-arbitrage regime. P-value reflects the empirical p-value of the LLR statistic based on Monte Carlo simulations. Observations are based on the TAR model (in general the observations of the AR model are the same, except in some cases where more lags were needed to correct for serial correlation). Both TAR and AR models are corrected for heteroskedasticity and serial correlation. ${ }^{* *},{ }^{* *}$, * refer to significance at the one, five, and ten percent level, respectively.

\begin{tabular}{|c|c|c|c|c|c|c|c|c|}
\hline \multirow[t]{2}{*}{ Country } & \multirow[t]{2}{*}{ Stock } & \multirow[t]{2}{*}{ Obs. } & TAR & TAR & TAR & TAR & TAR & AR \\
\hline & & & Thres & Half-life & LLR & Percent in & P-value & Half-life \\
\hline \multirow[t]{7}{*}{ Argentina } & $\begin{array}{l}\text { ypf } \\
\text { pze }\end{array}$ & $\begin{array}{c}1,545 \\
496\end{array}$ & $\begin{array}{l}0.09 \\
1.25\end{array}$ & $\begin{array}{l}0.01^{* * * *} \\
0.95^{* * * *}\end{array}$ & $\begin{array}{c}13.24 \\
7.29\end{array}$ & $\begin{array}{c}9.81 \\
23.05\end{array}$ & $\begin{array}{l}0.00 \\
0.08\end{array}$ & $\begin{array}{l}0.39^{* * *} \\
1.72^{* * * *}\end{array}$ \\
\hline & teo & 1,522 & 0.02 & $0.56^{* * * *}$ & 0.99 & 4.08 & 0.64 & $0.59 * * *$ \\
\hline & $\operatorname{tar}$ & 1,515 & 0.10 & $0.10^{* * *}$ & 9.29 & 9.98 & 0.02 & $0.30^{* * *}$ \\
\hline & $\operatorname{tgs}$ & 1,482 & 0.11 & $0.80^{* * *}$ & 4.93 & 7.25 & 0.21 & $0.89 * * *$ \\
\hline & bfr & 1,971 & 0.01 & $0.49 * * *$ & -0.46 & 1.87 & 0.95 & $0.63 * * *$ \\
\hline & mgs & 558 & 0.40 & $0.48^{* * *}$ & 4.25 & 5.73 & 0.23 & $0.67 * * *$ \\
\hline & irs & 1,429 & 0.05 & $0.63^{* * *}$ & 8.64 & 6.38 & 0.03 & $0.67 * * *$ \\
\hline \multirow[t]{24}{*}{ Brazil } & $\mathrm{pbr}$ & 726 & 0.11 & $0.62^{* * *}$ & 1.19 & 3.27 & 0.76 & $0.77^{* * *}$ \\
\hline & pbra & 674 & 0.06 & $0.66 * * *$ & 2.66 & 1.60 & 0.41 & $0.73 * * *$ \\
\hline & rio & 406 & 0.48 & $0.51^{* * *}$ & 11.06 & 10.77 & 0.00 & $1.26^{* * *}$ \\
\hline & itu & 489 & 0.18 & $0.38 * * *$ & 3.08 & 4.35 & 0.45 & $0.42 * * *$ \\
\hline & tsp & 529 & 1.85 & $0.46^{* * *}$ & 4.27 & 22.63 & 0.27 & $1.35^{* * *}$ \\
\hline & erj & 755 & 0.30 & $0.28 * * *$ & 8.47 & 9.82 & 0.04 & $0.60^{* * *}$ \\
\hline & the & 1,139 & 0.17 & $0.48^{* * *}$ & 5.64 & 7.18 & 0.08 & $0.62 * * *$ \\
\hline & sid & 1,128 & 0.03 & $0.36 * * *$ & 0.16 & 1.32 & 0.84 & $0.52 * * *$ \\
\hline & ara & 1,633 & 0.16 & $1.17 * * *$ & 2.27 & 9.10 & 0.50 & $1.37 * * *$ \\
\hline & ggb & 1,118 & 0.07 & $0.41^{* * * *}$ & 0.97 & 2.15 & 0.59 & $0.45^{* * *}$ \\
\hline & vср & 795 & 0.03 & $0.63 * * *$ & -0.03 & 1.04 & 0.95 & $0.65 * * *$ \\
\hline & cig & 459 & 0.06 & $1.42 * * *$ & 0.64 & 1.08 & 0.96 & $1.51^{* * *}$ \\
\hline & ubb & 960 & 0.06 & $0.54 * * *$ & 0.51 & 1.92 & 0.87 & $0.57 * * *$ \\
\hline & cbd & 1,273 & 0.83 & $0.25 * * *$ & 15.49 & 33.08 & 0.00 & $0.75^{* * *}$ \\
\hline & bak & 780 & 0.1 & $0.43 * * *$ & 2.67 & 1.28 & 0.30 & $0.48 * * *$ \\
\hline & tro & 1,212 & 0.04 & $0.47 * * *$ & 1.12 & 1.12 & 0.52 & $0.49 * * *$ \\
\hline & emt & 1,115 & 0.03 & $0.43 * * *$ & -1.13 & 1.24 & 1.00 & $0.45^{* * *}$ \\
\hline & elp & 1,143 & 0.18 & $1.03^{* * * *}$ & 5.79 & 5.51 & 0.14 & $1.20^{* * *}$ \\
\hline & $\mathrm{tmb}$ & 1,120 & 0.05 & $0.51^{* * *}$ & 2.60 & 1.60 & 0.38 & $0.53^{* * *}$ \\
\hline & ugp & 735 & 0.09 & $0.95 * * *$ & 5.16 & 1.52 & 0.19 & $1.35^{* * *}$ \\
\hline & tsu & 1,136 & 0.08 & $0.52 * * *$ & 4.39 & 2.75 & 0.26 & $0.56 * * *$ \\
\hline & tnd & 1,029 & 0.22 & $0.58 * * *$ & 3.54 & 5.66 & 0.26 & $0.69 * * *$ \\
\hline & tbe & 1,044 & 0.34 & $0.51^{* * *}$ & 8.96 & 6.42 & 0.03 & $0.64 * * *$ \\
\hline & tcn & 1,039 & 0.3 & $0.55 * * *$ & 4.55 & 5.79 & 0.17 & $0.67 * * *$ \\
\hline \multirow[t]{12}{*}{ Chile } & san & 1,647 & 0.07 & $0.82^{* * *}$ & 2.93 & 3.34 & 0.43 & $0.89 * * *$ \\
\hline & eni & 1,237 & 0.25 & $0.74 * * *$ & 15.08 & 14.60 & 0.00 & $1.03 * * *$ \\
\hline & eоc & 1,355 & 0.15 & $0.64 * * *$ & 6.10 & 7.80 & 0.09 & $0.80^{* * *}$ \\
\hline & ctc & 1,361 & 0.13 & $0.57 * * *$ & 7.90 & 10.57 & 0.03 & $0.75 * * *$ \\
\hline & akoa & 753 & 0.16 & $0.77 * * *$ & 3.06 & 3.98 & 0.43 & $0.87 * * *$ \\
\hline & dys & 1,166 & 0.31 & $0.40 * * *$ & 15.58 & 12.77 & 0.00 & $0.66 * * *$ \\
\hline & cu & 1,109 & 0.02 & $0.76^{* * * *}$ & 1.17 & 0.99 & 0.77 & $0.77 * * *$ \\
\hline & lfl & 447 & 1.91 & $0.30 * * *$ & 2.28 & 22.34 & 0.61 & $1.11^{* * *}$ \\
\hline & $\mathrm{sqm}$ & 1,136 & 0.20 & $0.50 * * *$ & 7.96 & 12.87 & 0.05 & $0.66^{* * *}$ \\
\hline & lq & 610 & 0.13 & $1.42 * * *$ & 1.58 & 3.35 & 0.82 & $1.52 * * *$ \\
\hline & mys & 1,068 & 0.70 & $0.35 * * *$ & 20.83 & 20.88 & 0.00 & $0.79^{* * *}$ \\
\hline & gnr & 618 & 0.15 & $0.39 * * *$ & 2.19 & 3.30 & 0.59 & $0.52 * * *$ \\
\hline \multirow[t]{2}{*}{ Indonesia } & tlk & 1,118 & 0.09 & $0.88 * * *$ & 3.69 & 2.69 & 0.28 & $1.06 * * *$ \\
\hline & iit & 805 & 0.25 & $1.95^{* * *}$ & 6.62 & 8.63 & 0.08 & $2.21^{* * *}$ \\
\hline \multirow[t]{2}{*}{ Korea } & $\mathrm{kb}$ & 496 & 0.10 & $0.35 * * *$ & 5.10 & 6.72 & 0.11 & $0.45^{* * *}$ \\
\hline & han & 344 & 0.33 & $2.95 * * *$ & 5.23 & 2.12 & 0.10 & $1.98^{* * *}$ \\
\hline Mexico & amo & 467 & 0.33 & $1.20 * * *$ & 4.57 & 4.16 & 0.21 & $1.53 * * *$ \\
\hline & $a m x$ & 556 & 0.18 & $0.95 * * *$ & 12.29 & 7.70 & 0.01 & $1.66^{* * *}$ \\
\hline & $c \mathrm{CX}$ & 405 & 0.06 & $0.85 * * *$ & 3.38 & 2.54 & 0.38 & $1.07 * * *$ \\
\hline & tv & 1,932 & 0.05 & $0.52 * * *$ & 4.05 & 6.24 & 0.14 & $0.67 * * *$ \\
\hline & $\mathrm{fmx}$ & 1,301 & 0.02 & $0.45 * * *$ & 0.30 & 1.73 & 0.71 & $0.48 * * *$ \\
\hline & kof & 727 & 0.12 & $0.36^{* * * *}$ & 5.43 & 3.31 & 0.13 & $0.59 * * *$ \\
\hline & ekt & 1,566 & 0.07 & $0.61 * * *$ & 1.07 & 3.81 & 0.75 & $0.75 * * *$ \\
\hline & imy & 643 & 0.42 & $0.38 * * *$ & 13.88 & 8.08 & 0.00 & $0.67 * * *$ \\
\hline & msk & 896 & 0.39 & $0.58 * * *$ & 9.55 & 10.93 & 0.00 & $1.42 * * *$ \\
\hline & $\operatorname{sim}$ & 490 & 0.56 & $0.55^{* * *}$ & 6.53 & 2.89 & 0.07 & $0.40^{* * *}$ \\
\hline & $\mathrm{mcm}$ & 968 & 0.25 & $0.20^{* * *}$ & 2.32 & 6.27 & 0.52 & $0.95 * * *$ \\
\hline & sab & 510 & 0.06 & $0.70^{* * *}$ & 3.50 & 1.12 & 0.33 & $0.73^{* * *}$ \\
\hline & saj & 1,210 & 0.07 & $0.87 * * *$ & 2.10 & 3.89 & 0.53 & $0.96 * * *$ \\
\hline Russia & tht & 764 & 0.06 & $0.58 * * *$ & 2.18 & 1.73 & 0.39 & $0.89 * * *$ \\
\hline & ros & 1,210 & 0.15 & $0.61 * * *$ & 2.71 & 3.89 & 0.43 & $0.90^{* * *}$ \\
\hline South Africa & ssl & 1,260 & 0.20 & $0.77 * * *$ & 3.72 & 8.82 & 0.28 & $0.93 * * *$ \\
\hline & au & 1,631 & 0.05 & $0.68^{* * * *}$ & 3.20 & 2.65 & 0.38 & $0.72^{* * *}$ \\
\hline & gfi & 1,525 & 0.12 & $0.74 * * *$ & 2.27 & 3.12 & 0.51 & $0.81^{* * *}$ \\
\hline & hmy & 1,267 & 0.16 & $0.68^{* * *}$ & 4.52 & 4.48 & 0.28 & $0.75^{* * *}$ \\
\hline & spp & 790 & 0.06 & $0.77 * * *$ & 0.68 & 1.37 & 0.84 & $0.82 * * *$ \\
\hline & dro & 987 & 0.12 & $1.57 * * *$ & 3.94 & 2.29 & 0.29 & $1.64 * * *$ \\
\hline & $\operatorname{ran}$ & 343 & 0.82 & $1.27 * * *$ & 2.11 & 3.62 & 0.59 & $1.52^{* * *}$ \\
\hline Venezuela & vnt & 966 & 0.12 & $0.90^{* * *}$ & 3.43 & 5.52 & 0.43 & $0.99 * * *$ \\
\hline & mav & 723 & 1.23 & $0.92 * * *$ & 10.63 & 18.96 & 0.00 & $1.69 * * *$ \\
\hline
\end{tabular}




\title{
Appendix Table 3 - Controls on Stock Market Transactions
}

\begin{abstract}
Argentina
On December 2, 2001, controls on capital outflows were introduced as one of the measures of the "corralito". All investors, both foreign and domestic were prohibited from transferring funds abroad, wire transfers required central bank approval and foreign currency futures transactions were prohibited. Exactly one year later, the corralito was lifted and capital was allowed to leave the country, albeit some restrictions on capital outflows remained. From June 2003 onwards, virtually all controls were eliminated.
\end{abstract}

\section{Chile}

In July 1995, secondary DRs became subject to the Unremunerated Reserve Requirement (URR) that had covered several types of capital inflows since its introduction in June 1991. A 30 percent reserve deposit that earned no interest needed to be paid, with the holding equal to the loan maturity with a minimum of three months and a maximum of one year. Primary DRs were considered capital additions and were therefore never subject to the URR. With markets in turmoil and the Chilean peso under attack, the reserve requirement was lowered to ten percent in June 1998. In August of that year, the URR was eliminated for secondary DRs (and in September reserve requirements on all inflows were eliminated).

\section{Indonesia}

When the first Indonesian company introduced a publicly traded DR, the Indonesian capital market was largely liberalized. However, foreigners were only allowed to purchase up to 49 percent of all companies' listed shares. In September 1997, this restriction was lifted and foreign investors could purchase unlimited domestic shares (except banking shares).

\section{Korea}

When the first publicly traded DR was introduced, there existed restrictions on foreign investment in the stock markets. These ceilings were gradually increased over time. In May 1998, the government lifted the foreign investment restrictions on Korean securities, except on Kepco, Posco, mining and airtransportation companies, and information and telecommunication companies. For some companies, foreign investment ceilings are still in place. For firms cross-listed using Depositary Receipts, an additional restriction was in place. Although there was no restriction on the conversion of DRs into underlying shares, until January 1999 the conversion of underlying shares into DRs was restricted (e.g. approval was needed by the issuing company's board). From January 1999, Korean companies that issued DRs, starting with Kookmin Bank, began to allow free conversion. As of November 2000, Korea changed its regulations so that underlying shares can be converted into DRs without board approval as long as "the number of underlying shares that can be converted into DRs" is less than "the number of underlying shares that have been converted from DRs."

\section{South Africa}

In the early 1990s, there existed a dual exchange rate system in South Africa (introduced in 1979 and temporarily abandoned in 1983), with a commercial rate subject to intervention by the monetary authorities and a free floating financial rate (usually at a discount from the commercial rate). The financial rate operated with respect to the local sale and redemption proceeds of South African securities and other investments in South Africa owned by nonresidents, capital remittances by emigrants and immigrants, and approved outward capital transfers by residents. Exchange control restrictions applied to financial rand accounts of non-residents of the Common Monetary Area (CMA). Local sales and redemption proceeds of South African securities and other investments owned by nonresidents had to be credited to these accounts. Funds in these financial rand accounts could be used freely for reinvestment in locally quoted securities (which could be exported and sold abroad) or for acquiring quoted central government, municipal, or public utility stocks. On application and approval, financial rand could be used by nonresidents for the purchase of other assets. Outward transfers of capital by residents to destinations outside the CMA required approval of the central bank. Transfers of residents for the purchase of South African or other shares on foreign stock exchanges were generally not permitted except in amounts not exceeding R5,000. In March 1995, the financial rand and the currency exchange system were abolished. The 15 percent tax on remittances by non-resident shareholders was also eliminated.

\section{Venezuela}

In June 1994, the foreign exchange market was closed and controls on capital outflows were introduced to stop the severe speculative attacks against the Bolivar. The controls implied an outright prohibition of capital outflows, including the repatriation of nonresident investment, but excluding flows related to the repayment of external debt. Furthermore, the measures restricted the availability of foreign exchange for import payments. By May 1996, these controls were abolished. In January 2003, exchange rate trading was suspendend, limits to dollar purchases were introduced. Originally the measure was introduced as a temporary measure, but it is still in place accompanied by stingent capital controls introduced in February 2003.

Sources: Bloomberg, IFC Emerging Markets Factbook, IMF Annual Report on Exchange Arrangements and Exchange Restrictions, Korea's Financial Supervisory Service's Regulation on Supervison of Securities Business. 